\title{
Optical Diagnostics of Pre-Chamber Combustion with Flat and Bowl-in Piston Combustion Chamber
}

\author{
Author, co-author (Do NOT enter this information. It will be pulled from participant tab in \\ MyTechZone) \\ Affiliation (Do NOT enter this information. It will be pulled from participant tab in MyTechZone)
}

\begin{abstract}
Pre-chamber Combustion (PCC) extends the lean operation limit operation of spark ignition (SI) engines, thus it has been of interest for researchers as a pathway for increased efficiency and reduced emissions. Optical diagnostic techniques are essential to understand the combustion process, but the engine components such as the piston geometry, are often different from real engines to maximize the optical access. In this study, ignition and subsequent main chamber combustion are compared in an optically accessible PCC engine equipped with a "flat" and a real engine-like "bowl" piston geometry. An active fueled narrow throat pre-chamber was used as the ignition source of the charge in the main-chamber, and both chambers were fueled with methane. Three pre-chamber fuel effective mean pressure (FuelMEP) ratios (PCFR) namely $6 \%, 9 \%$ and $11 \%$ of the total amount of fuel were tested at two global excess air ratios $(\lambda)$ at values of 1.8 and 2.0. The optical engine configuration included a metal liner and a quartz piston, and it was operated for 100 consecutive firing cycles, allowing stable emissions measurements. A high-speed intensified camera was used to record the $\mathrm{OH}^{*}$ chemiluminescence of the main-chamber combustion. The camera was operated at $50 \mathrm{kHz}$, resulting in a resolution smaller than 0.2 Crank Angle Degree (CAD), at the engine speed of 1200 revolutions per minute (RPM). Both pistons exhibited similar pre-chamber pressures and an equal pressure difference between pre- and mainchamber $(\Delta P)$ at the peak pressure inside the pre-chamber. The free reacting jet behavior was also comparable between the two piston geometries. However, the flat combustion chamber resulted in a shorter free jet time because of the early reacting jet-piston interaction. The interaction also slowed down the combustion propagation and increased the combustion duration for the flat piston.
\end{abstract}

\section{Introduction}

In recent years, the emissions policies have become stricter, imposing $32 \%$ reduction in greenhouse emissions from transport sector within the European Union[1]. Vehicle manufacturers have then the challenge to increase internal combustion engines (ICE) efficiency by means of combustion novel modes, post-treatment emission reductions, and substituting renewable fuels to existing fuels. One of the trends is to operate the engine with a lean mixture [2]. This strategy avoids using intake flow restrictions to control the load, increasing the gas-exchange efficiency. The major concern on burning lean mixtures lies in the ignition source, which requires high energy to reduce the cyclic variability. Some innovative ignition sources have been proposed in the last years: plasma igniters [3], laser-induced ignition [4], corona ignition systems[5], and prechambers systems.

Page 1 of 16
Research in pre-chamber ignitions reported advantages of the system compared to other ignition sources. The differentiating element of this technology is the reduction of the combustion duration and the extension of the lean limit, without increasing NOx emissions [6]. The concept is based on a small volume, where the combustion starts and then propagates through multiple nozzle holes to the mainchamber in the form of reacting jets. These jets first extend inside the main-chamber and then, ignite the mixture at multiple points, providing overall shorter combustion duration.

Several investigations have been conducted to understand the prechamber combustion physics, scaling up in complexity from constant volume chambers to real engines. These studies included the jets' ignition mechanisms of the main charge[7], the jet-to-jet interaction [8], the pre-chamber geometry influence[9], which are essential topics for the practical application. The majority of these studies have been followed by modeling progress to enhance understanding of the ignition and combustion processes[10-12].

Models require experimental data to validate their estimated performance. Data from metal engine experiments are generally limited to pressure traces and exhaust gas emissions. Optical engine studies have been established as a secondary information source, which can provide velocity fields, temperature, and radical composition [13-17]. This extended information is vital for complete validation. Although the thermodynamic conditions could differ between real and optical engines, several investigations tried to reduce the gap, to obtain comparable results to a full metal engine operation [14].

One of the differences between optical and metal engine configurations usually is the piston geometry, differing in material and shape. Standard piston shapes contain geometrical complexities (curves, number of edges, etc.), which generate image distortions, limiting the field of view. The curvatures also increase the complexity of the laser-based technique because of laser reflections on the multiple surfaces.

In the standard piston geometry (bowl in piston) used in this study, the pre-chamber jets targeted the base of the bowl to improve the mixing of the emerging pre-chamber jets, like a Diesel engine. This type of geometry has several curvatures which causes distortions at the pip and the bowl walls. All the listed constraints motivate the researchers to use simplified combustion chambers for optical engines, which are usually cylindrical bowl or flat pistons $[18,19]$. The effects of different combustion chambers - a "real" bowl-inpiston and an "optical purpose" flat piston - on ignition and combustion in a PCC engine are reported in the present paper. The 
comparison is intended to determine any difference in the mainchamber combustion between the two piston geometries.

\section{Methodology}

\section{Experimental Apparatus}

The research engine used in this study was converted from a heavyduty diesel engine (Volvo D13C500). The base engine is an inline-six cylinder engine and only one of the cylinders was operated, with the remaining cylinders de-activated by removing the intake and exhaust valves. The engine specifications are reported in Table 1 . The original piston and the liner were replaced by optically accessible parts. Figure 1 presents the schematic diagram of test rig. The engine was attached to an electrical dynamometer, which sets constant engine speed conditions for the experiments.

Table 1. Engine specifications.

\begin{tabular}{|c|c|c|}
\hline Valve mechanism & \multicolumn{2}{|c|}{ Single Overhead Cam } \\
\hline Bore & 131 & $\mathrm{~mm}$ \\
\hline Stroke & 158 & $\mathrm{~mm}$ \\
\hline Connection Rod Length & 255 & $\mathrm{~mm}$ \\
\hline Cylinder Displacement Volume & 2.1 & Liter \\
\hline Clearance Volume & 0.2 & Liter \\
\hline Number of Valves & 4 & {$[-]$} \\
\hline Intake Valve Timing & Open & -330 CAD aTDC \\
\cline { 2 - 3 } & Close & -170 CAD aTDC \\
\hline Exhaust Valve Timing & Open & 180 CAD aTDC \\
\cline { 2 - 3 } & Close & 340 CAD aTDC \\
\hline
\end{tabular}

The air intake line (blue line in Figure 1) was instrumented to measure and control essential variables: mass flow rate, pressure, and temperature. The exhaust line (red line in Figure 1) was also monitored for temperature and pressure, and it is linked with an emissions analyzer. The test rig was designed to operate with gaseous fuel for two different lines, pre- and main-chamber. Both lines have the capability to measure and control the fuel flow into the engine.

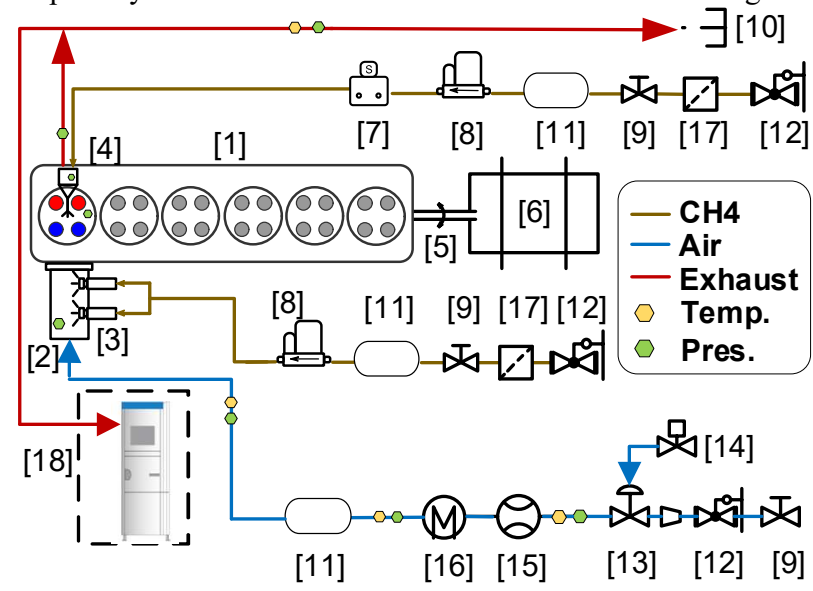

Figure 1. Experimental setup: 1. Engine, 2. Intake, 3. PFI, 4. Pre-chamber,5. Cardan shaft, 6. Dynamometer, 7. Gas block injector, 8. Mass flow controller, 9. Valve, 10. Vent to the atmosphere, 11. Damping vessel, 12. Pressure regulator, 13. Throttle Control Valve, 14. Pneumatic control valve, 15. Mass flow meter, 16. Air heater, 17. Fuel filter, 18. Emission analyzer

All the sensors and actuators are controlled from a LabVIEW remote interface. During the combustion process, the in-cylinder pressure is

Page 2 of 16 temporally captured based on a crankshaft mounted rotary encoder, which gives a $0.2 \mathrm{CAD}$ resolution. The authors reported a further detailed description of the test rig in a previous paper [20].

The engine's optical configuration has a Bowditch extension [17], which in combination with a quartz body piston generates bottom optical access to the combustion chamber. The quartz piston is mounted in a titanium piston holder with a set of dry rings to seal the combustion chamber. The extension, piston holder, and the piston reciprocate inside a metal liner and an optical liner assembly, as shown in Figure 2.

Figure 2 shows the layout of the optical engine setup. A La Vision High-Speed IRO system, coupled with a high-speed camera (Photron Fastcam SA4), was used to record the combustion process from the bottom of the piston. The system was equipped with a 320/40 nm BrightLine ${ }^{\circledR}$ single-band bandpass filter. The wavelength range of this filter covers the $\mathrm{OH}^{*}$ chemiluminescence. The recording frame speed was set to 50000 frames per second, which resulted in a resolution smaller 0.2 CAD for a constant engine speed of 1200 RPM.

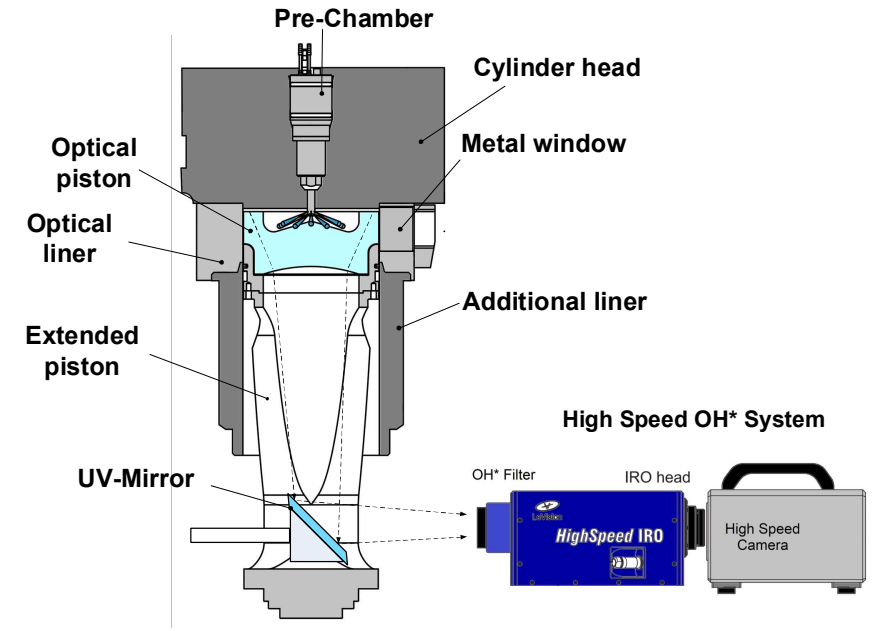

Figure 2. Optical configuration of the engine and bottom optical access.

\section{Image Processing}

The first step in the image processing included background subtraction and a gaussian filter. Then, the images were centered with the pre-chamber tip, which was recognized based on the four visible reacting jets. For the bowl piston images, a distortion correction was applied based on a method reported by Tang et al. [21].

For the reacting jet penetration, the jet at two o'clock (see Figure 3) was masked and binarized using the global image threshold from the Otsu's method. From the binarized image, the biggest region (continuous white area) was identified as the projected reacting jet, and its tip was considered on the farthest pixel from the center. The projected penetration was calculated from the image center until the reacting jet tip. Finally, the real penetration was calculated considering the umbrella angle of the nozzles, as shown in Figure 3.

Finally, to compare the reacting jet shape, the Structural Similarity index [22] was used. This index compares the luminance, contrast and structure of the two images. The range of the index is from zero to one, been one when the two images are identical. 


\section{Combustion Chambers}

The aim of this study is the comparison of the pre-chamber reacting jets on two different combustion chambers (see Figure 4). The "bowlin-piston" combustion chamber is the baseline for this study, and it is similar to the geometry used in the all-metal engine experiments. The second combustion chamber uses a flat piston, which is frequently employed in optical diagnostic since image distortion is minimum with this piston.

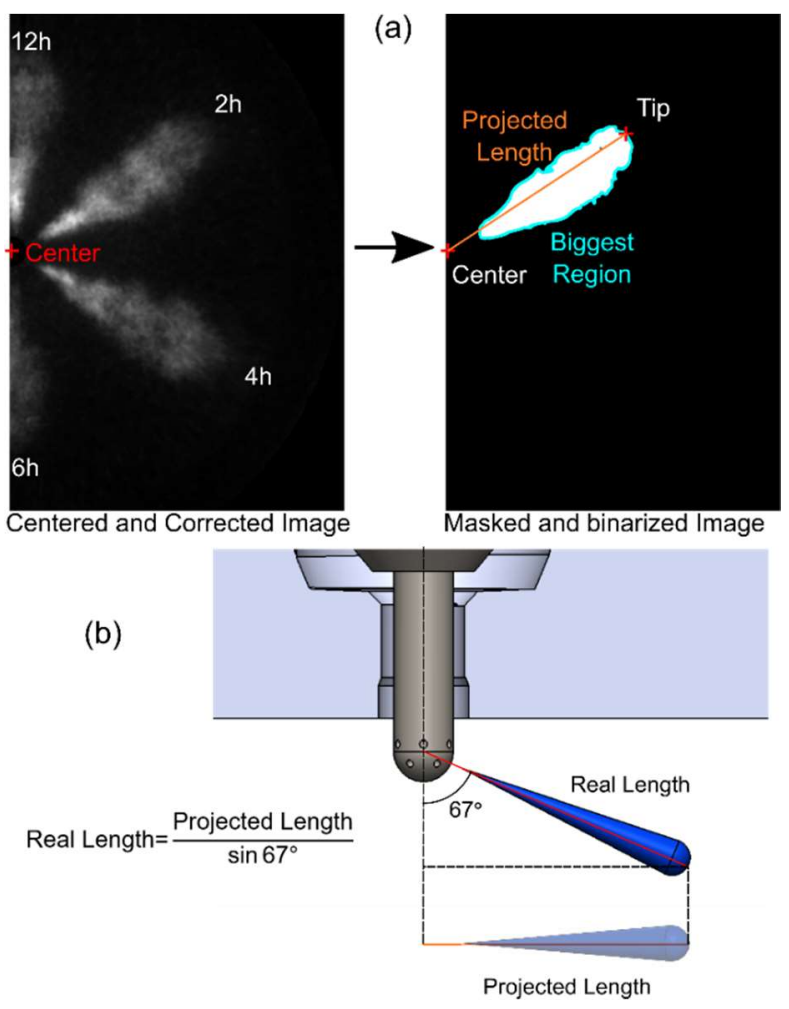

Figure 3 (a) Image processing. (b) Calculation of the reacting jet penetration

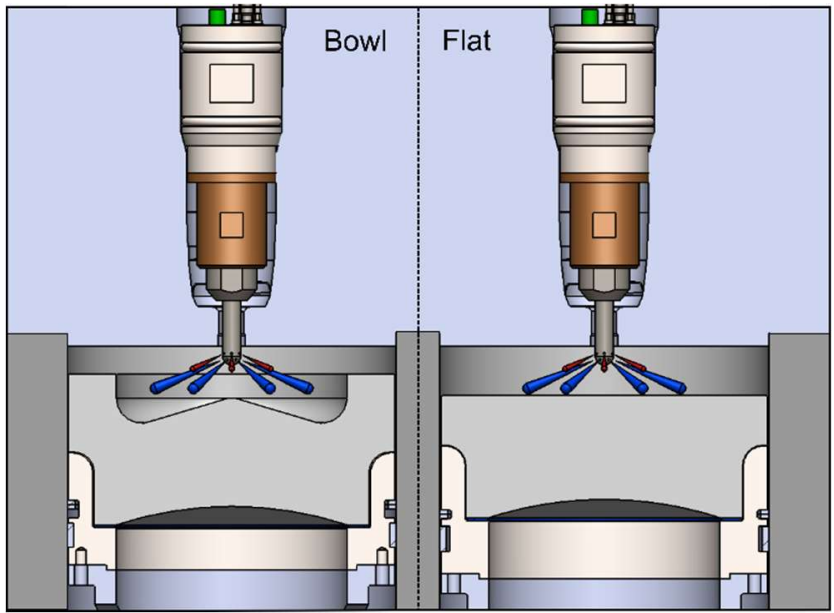

Figure 4. Tested combustion chambers. Left: Bowl piston, Right: Flat piston. The figure illustrates the early jet-piston interaction for the Flat combustion chamber around -10 CAD aTDC.

Bowl: It is a bowl in shape with an omega profile. This kind of piston has been used as a reference for the KAUST pre-chamber

Page 3 of 16 studies[20,23-25]. The optical configuration has differences compared to the metal engine piston because it requires reducing the bowl volume to compensate for the blow-by and assure a similar effective compression ratio (see appendix A1). The jet's tilt angle is designed to collide with the bottom of the bowl, and then, the combustion propagates to the center of the combustion chamber and the squish volume.

Flat: It is the simplest combustion chamber that could be designed. It avoids distortion on the images of the combustion chamber. Compared to the bowl geometry, the clearance volume distribution resulted in a shorter jet path and earlier jet and piston interaction. Its simplicity does not disturb the turbulence level from the inlet port significantly during the intake and expansion process [26].

\section{Operating Conditions}

The effective compression ratios were found to be, 11.7:1 for the bowl piston and 11.4:1 for the flat piston. The difference lies in the effectiveness of the sealing system. The maximum motoring pressure (see Figure 5) was kept similar in the two combustion chambers to assure comparability by adjusting the intake pressure while keeping the intake temperature constant, as reported in Table 2. The TDC motoring temperature was calculated using the ideal gas equation. The difference between the two combustion chamber motoring temperatures was less than $10 \mathrm{~K}$. This TDC pressure match recreates similar thermodynamic conditions for the two combustion chambers.

The air trapped mass for the flat combustion chamber was higher (around 9\%), and therefore, the fuel addition was also higher for the flat combustion chamber. The remaining engine conditions were constant for the two experiments. At each operating point 100 consecutive cycles were recorded after the engine reached steadystate conditions. With this methodology, stable emissions recording was guaranteed. A test matrix with two different $\lambda$ and three levels of PCFR was followed to compare the two combustion chambers. The PCFR is based on a Fuel Mean Effective Pressure (FuelMEP) Ratio between the pre-chamber and the total. PCFR and FuelMEP are defined in equations (1) and (2).

$$
\begin{gathered}
P C F R=\frac{F u e l M P C}{\text { FuelMEP }_{P C}+F u e l M E P_{M C}} \times 100 \\
\text { FuelMEP } P_{P C, M C}=\frac{\text { mass of fue }{ }_{P C, M C} \times \text { LHV of Fuel }}{\text { Engine Displacement Volume }}
\end{gathered}
$$

The test matrix (see Table 3) covers two lean conditions for the global excess air ratios $\left(\lambda_{\mathrm{Glo}}\right)$ conditions. The same range was covered with three different levels of PCFR. The operating modes were tested in the optical engine and a homologous metal engine. The motivation for repeating similar operation conditions in the metal engine, was to have a reference for a comparison of the emission analysis. The spark timing was fixed at -15 CAD aTDC to ease the comparison of the combustion chambers. In parallel studies carried out in the metal engine configuration [27], it was found that the difference for the MBT spark timing is minor (2 CAD) for the proposed operating points of the current study. 


\section{Heat Release Analysis and $\lambda_{\mathrm{PC}}$ Calculation}

The heat release analysis reported in this work was developed following the approach reported by Duong et al. [28], and it was detailed in ref. [20,24]. Besides, the analysis was validated and complemented with GT-Power simulations. The GT-Power model (see appendix A2) used for this study contemplates an improved version of the model used in previous studies [20,29]. In this case, the PCFR estimation was complemented, adding the pressure in the measured pre-chamber fuel line as input for the simulation. This updated model was reported by the authors in ref. [27]. The GTPower simulations were used in this study to estimate the $\lambda$ inside the pre-chamber at spark timing, air mass trapped, and temperature for the two combustion chambers in motoring conditions for matching the TDC pressure.

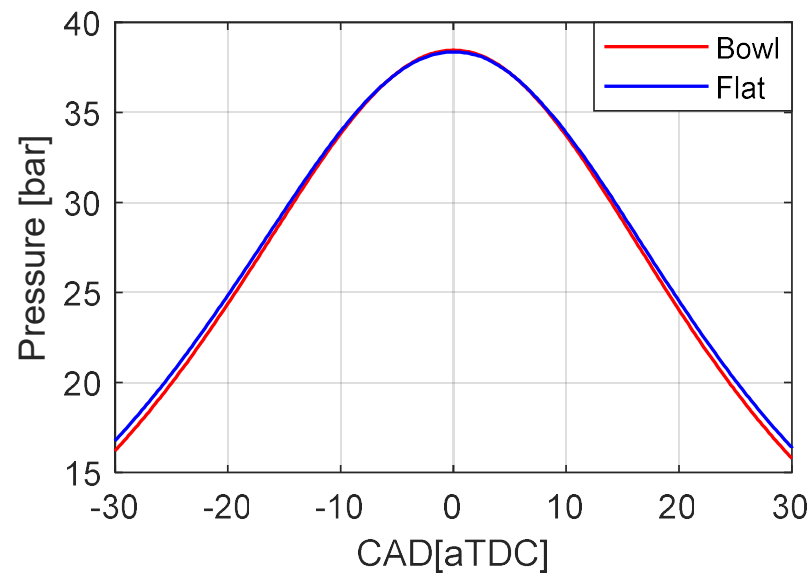

Figure 5. Comparison of motoring pressure traces between the two combustion chambers.

Table 2. Operating conditions for experiments.

\begin{tabular}{|c|c|c|c|}
\hline Piston Shape & Bowl & Flat & {$[-]$} \\
\hline Pressure at TDC & 38 & 38 & bar \\
\hline Bulk Temperature at TDC & 808 & 817 & $\mathrm{~K}$ \\
\hline Intake Pressure & 1.36 & 1.42 & bar \\
\hline Air trapped mass & 2.83 & 3.09 & $\mathrm{~g}$ \\
\hline Engine Speed & 1200 & 1200 & $\mathrm{RPM}$ \\
\hline Intake Temperature & 30 & 30 & ${ }^{\circ} \mathrm{C}$ \\
\hline Effective Compression Ratio & $11.7: 1$ & $11.4: 1$ & {$[-]$} \\
\hline Squish Height & 5.2 & 11.2 & $\mathrm{~mm}$ \\
\hline Piston Surface Area & 177.5 & 128.7 & $\mathrm{~cm}^{2}$ \\
\hline MC Fuel & \multicolumn{4}{|c|}{$\mathrm{CH}_{4}(99.5 \%$ purity $)$} \\
\hline MC Fuel SOI & -360 & -360 & $\mathrm{CAD}$ aTDC \\
\hline MC Fuel Press. & 7 & 7 & bar \\
\hline PC Fuel & \multicolumn{4}{|c|}{$\mathrm{CH}_{4}(99.5 \%$ purity) } \\
\hline PC Fuel SOI & -360 & -360 & bar \\
\hline PC Fuel Pressure & 7 & 7 & bar \\
\hline Spark Timing & -15 & -15 & CAD aTDC \\
\hline
\end{tabular}

Table 3. Test matrix.

\begin{tabular}{|c|c|c|c|}
\hline \multirow{2}{*}{$\lambda_{\text {Glo }}$} & \multicolumn{3}{|c|}{ PCFR [\%] } \\
\cline { 2 - 4 } & 6 & 9 & 11 \\
\hline 1.8 & $\bullet$ & $\bullet$ & $\bullet$ \\
\hline 2.0 & $\bullet$ & $\bullet$ & $\bullet$ \\
\hline
\end{tabular}

Page 4 of 16

\section{Pre-chamber}

The engine was equipped with a narrow throat pre-chamber [23] as the ignition source. The pre-chamber (see Figure 6) has the particularity of having a narrow throat ( $3.3 \mathrm{~mm}$ diameter), which connects the pre-chamber major volume and the nozzle holes. The pre-chamber was designed with a pre-chamber volume of $2.5 \%$ of clearance volume and with the ratio between the total nozzle area pre-chamber volume of $0.035 \mathrm{~cm}^{-1}$. These two parameters are in the range suggested by Gussack's [30].
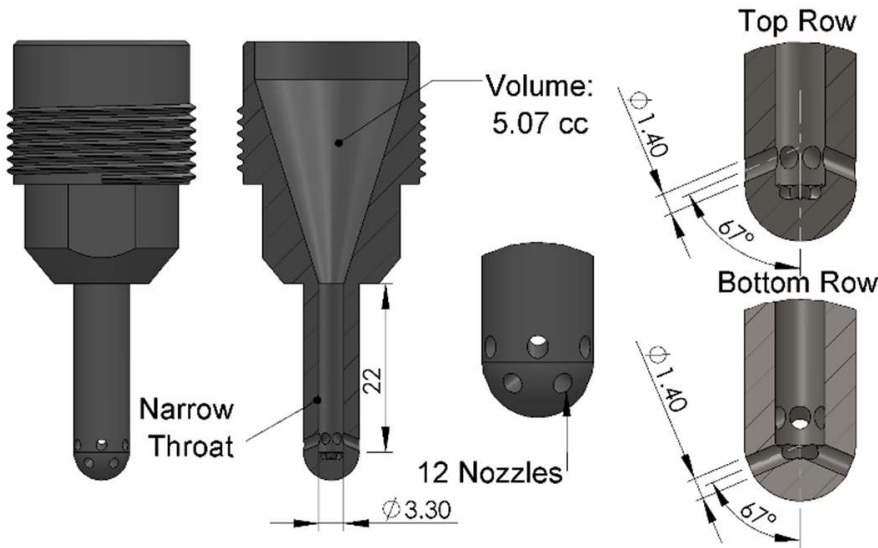

Figure 6 Pre-chamber internal geometry

The pre-chamber outline is designed to fit into the original fuel injector compartment. The assembly (see Figure 7) has three main components: pre-chamber, adaptor, and enclosure. The pre-chamber is screwed into the bronze adaptor, which houses spark plug (NGKER8EH), the pressure sensor (AVL GH15DK), and a gas line with a check valve (Lee 558) on top. An enclosure sits on top of the adaptor and protects the components from ingress of lubricating oil.

The pre-chamber fuel addition is a complex process, and it has three major elements: the Mass Flow Controller (MFC), which controls the mass of added fuel; the Gas block injector, which controls the Start of Injection (SOI) and duration of injection (DOI); and the Check Valve, which governs the mass interaction between the fuel line and the pre-chamber. The interaction of these three elements determines the final fuel addition.

The activation of the Gas block injector (Inj. Signal in Figure 8) pressurizes the fuel line between the block and the check valve (upstream the check valve). When this fuel line pressure is greater than the pre-chamber pressure, the check valve allows fuel flow to the pre-chamber. Therefore, the driven force for the pre-chamber fuel injection is the difference between the fuel line and pre-chamber pressure. This pressure difference is delayed with respect to the injection signal, as is shown in Figure 8. 

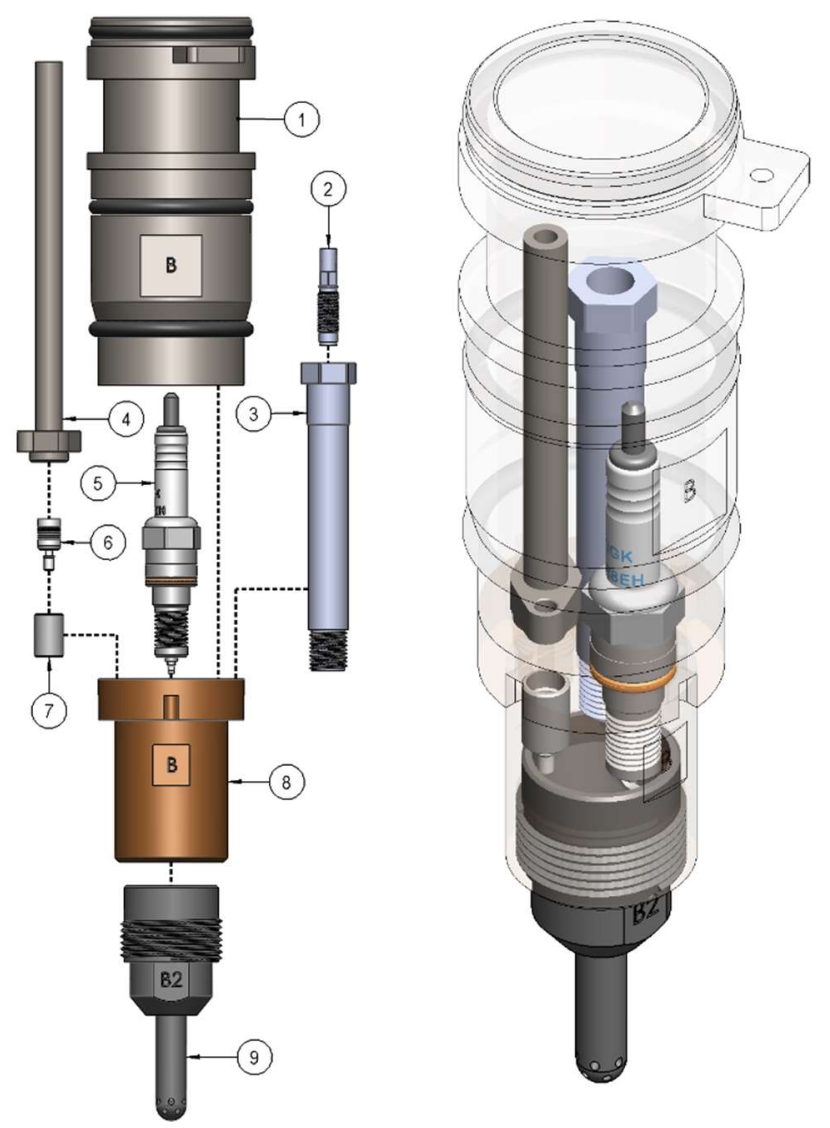

Figure 7. Pre-chamber Assembly (1) Enclosure, (2) Pressure sensor, (3) Pressure sensor adaptor, (4) Gas line, (5) Spark Plug, (6) Check valve, (7) Check valve sleeve, (8) Adaptor, (9) Pre-chamber
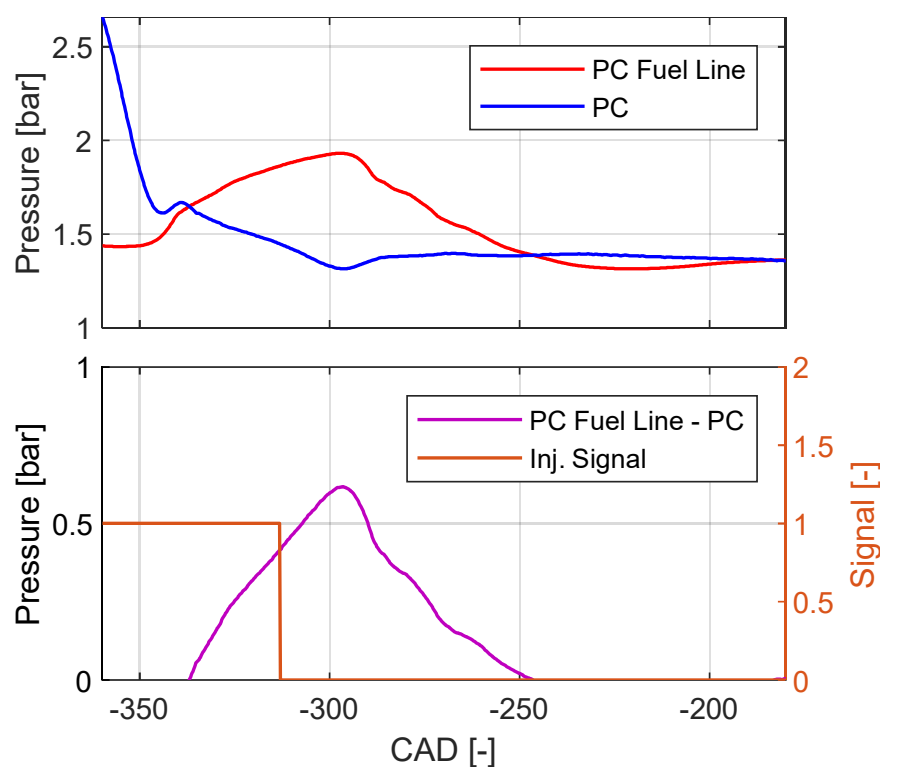

Figure 8 Pre-chamber fuel injection: pressure behavior

\section{Cycle Selection}

To compare the behavior of reacting jets issued from the pre-chamber into the main chamber between the two combustion chambers, cycles

Page 5 of 16 with similar pressure difference between the pre- and main-chamber $(\Delta P)$ were selected. This pressure difference is the driving force that ejects the pre-chamber jets into the main-chamber. The comparison process starts with selecting two cycles, one for each combustion chamber, which have similar pressure difference. To select these two cycles, the $\Delta P$, and its angular derivative were parameterized with six values (see Figure 9):

1. Maximum $\Delta P$.

2. Crank angle of maximum $\Delta P$.

3. Crank angle of $10 \%$ of maximum $\Delta P$.

4. Duration of the pre-chamber discharge.

5. Maximum $\mathrm{d}(\Delta P) / \mathrm{d} \theta$.

6. Crank angle of maximum $\mathrm{d}(\Delta P) / \mathrm{d} \theta$.

These six parameters were evaluated for all the recorded cycles, generating a multivariable dataset, and the Euclidean distance between all the samples combination was calculated. Then, the two lowest distance cycles from different piston-set were selected as the identical cycles. The six parameters were also used to study the similarity between the pre-chamber discharge process through a multiple scatter plot.
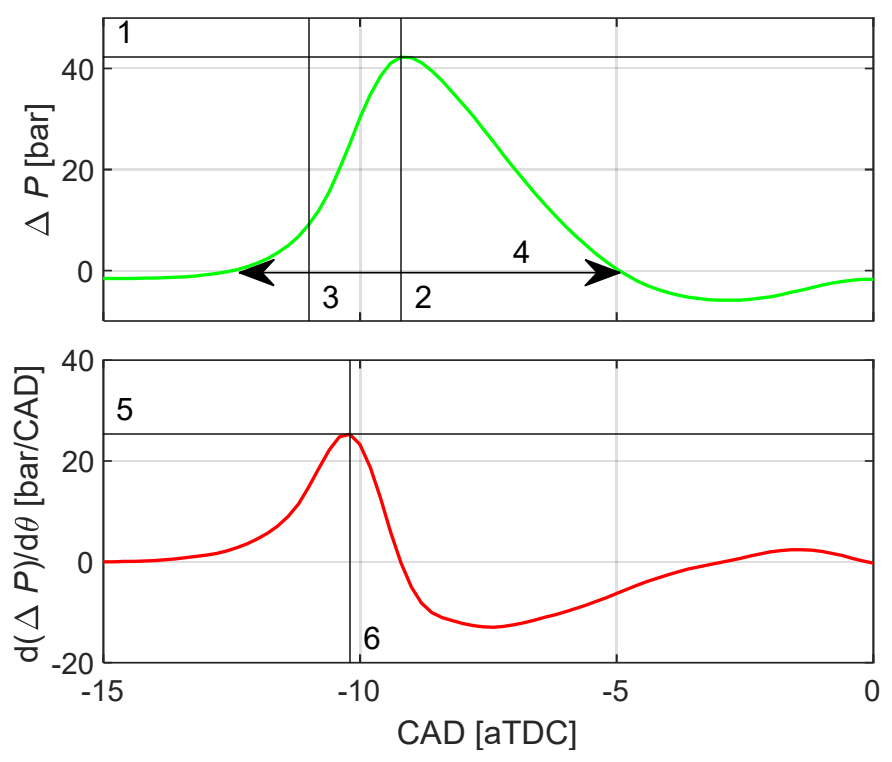

Figure 9. Six parameters variables of the pre-chamber discharge

\section{Results and Discussion}

\section{Heat Release Analysis}

The pre- and main-chamber pressure traces of the case at $\mathrm{PCFR}=6 \%$ and $\lambda_{\mathrm{Glo}}=1.8$, which will be considered as the reference case in the following, are reported in Figure 10 for both pistons. In both chambers, the pressures exhibit similar behavior until TDC for both pistons, despite the difference in combustion chamber geometry. The dissimilarity appears before the main-chamber pressure reaches its maximum; after this point, the flat piston pressure decrease is slower than the bowl combustion chamber. The reported behavior for the reference case is homogeneous for all the five remaining cases. 

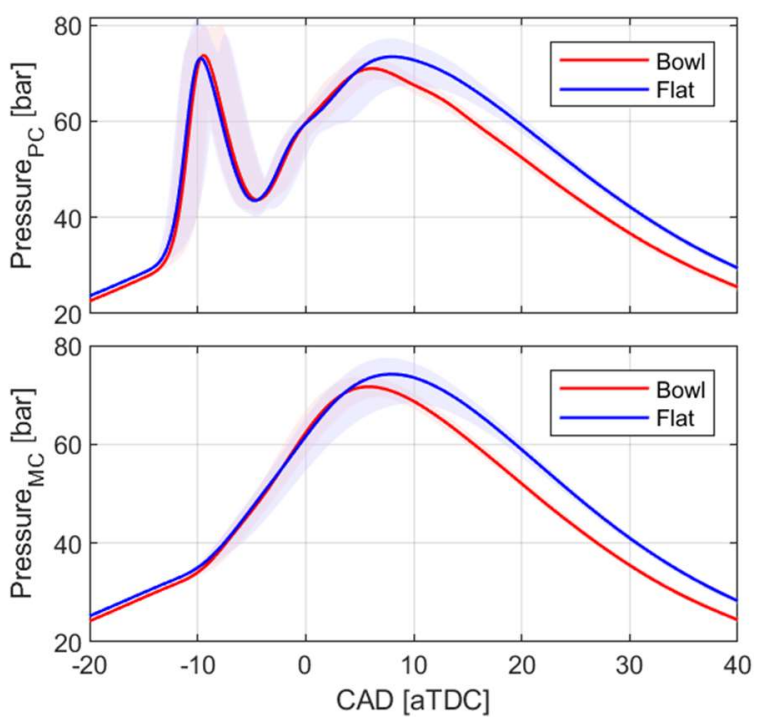

Figure 10 Pre- and Main-chamber pressure traces for the two combustion chambers. Conditions PCFR $=6 \%$ and $\lambda_{\text {Glo }}=1.8$.

The combustion behavior of the two chambers was also performed using the pre- and main-chamber rate of heat release (RoHR) as shown in Figure 11. Traces showed in Figure 11 correspond to the mean value of the hundred measured cycles, and the shadow corresponds to plus and minus one standard deviation. The Prechamber RoHR is similar in most of the cases. Although the average
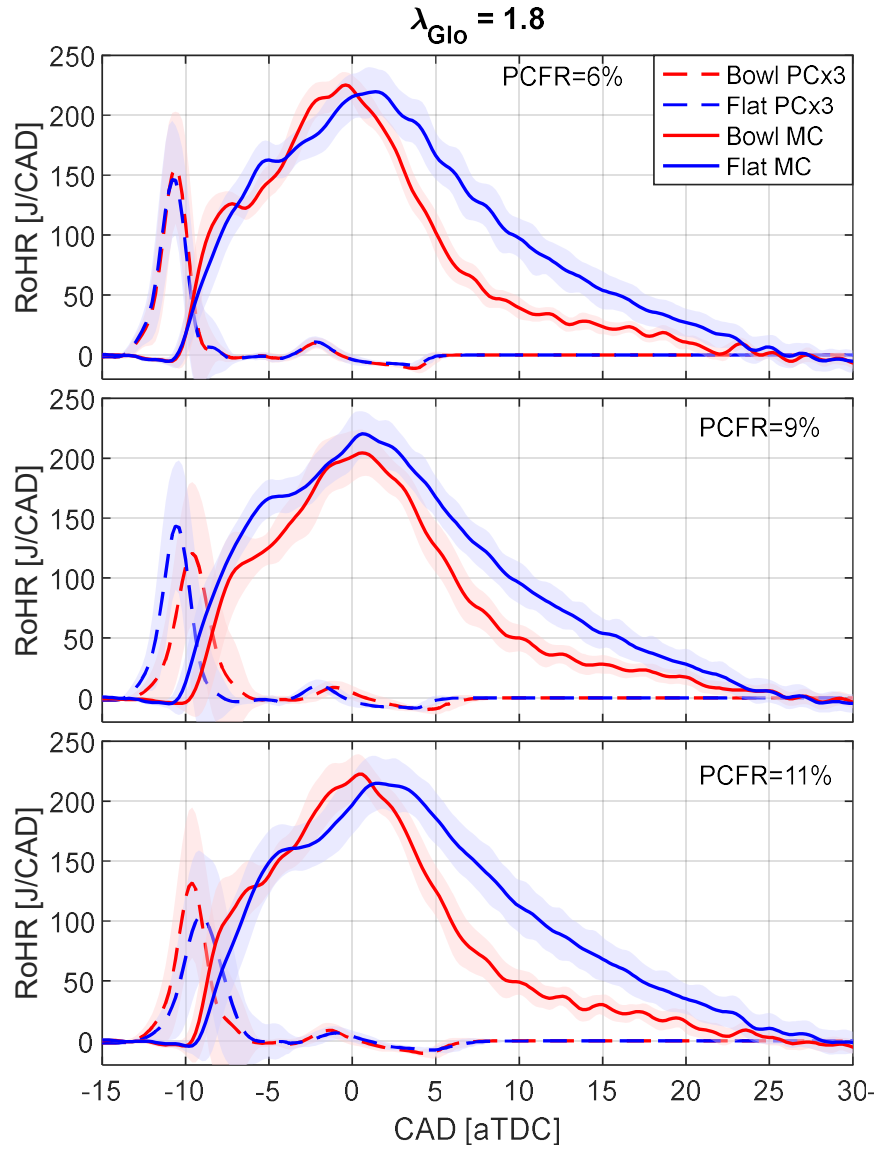

traces of $\mathrm{PCFR}=9 \%$ and $\mathrm{PCFR}=11 \%$ on $\lambda_{\mathrm{Glo}}=1.8$ present some differences regarding the pre-chamber combustion, the remaining four cases presented a similar pre-chamber RoHR. The estimation of the $\lambda_{\text {PC }}$ at spark timing does not show any significant differences between both piston geometries (see Table 4), evidence that supports the results of a similar pre-chamber heat release.

In contrast, the main-chamber RoHR presents notable differences between the two piston geometries. In the initial stage of the mainchamber RoHR (before TDC), the bowl combustion chamber exhibits faster combustion until it reaches a deceleration stage (around -7 CAD aTDC for the reference case). The two pistons have a similar RoHR until an inflection point for the flat piston (around -10 CAD aTDC for the reference case). Then, the flat has a slower heat release, and it also presents a deceleration stage, which is always later (around -5 CAD aTDC for the reference case) than the bowl combustion chamber case.

Table 4. Results of the $\lambda_{\text {PC }}$ for the tested cases. Values obtained from GTPower Simulations

\begin{tabular}{|c|c|c|c|c|}
\hline & \multicolumn{2}{|c|}{$\lambda_{\mathrm{Glo}}=\mathbf{1 . 8}$} & \multicolumn{2}{c|}{$\lambda_{\text {Glo }}=\mathbf{2 . 0}$} \\
\hline Piston & Bowl & Flat & Bowl & Flat \\
\hline PCFR [\%] & $\lambda_{\text {PC[-] }}$ & $\lambda_{\text {PC }[-]}$ & $\lambda_{\text {PC[-] }}$ & $\lambda_{\text {PC }[-]}$ \\
\hline 6 & 0.82 & 0.83 & 0.87 & 0.89 \\
\hline 9 & 0.76 & 0.78 & 0.81 & 0.80 \\
\hline 11 & 0.74 & 0.73 & 0.77 & 0.79 \\
\hline
\end{tabular}
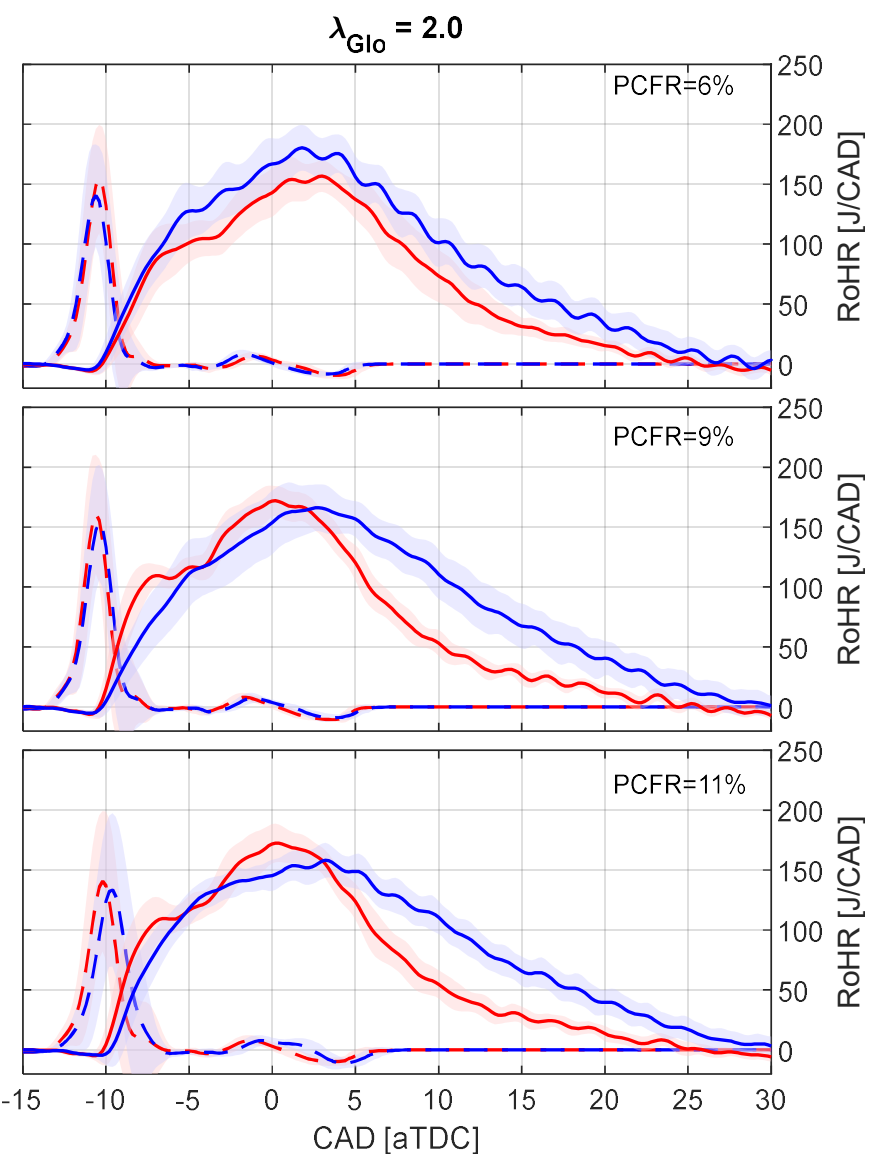

Figure 11 Pre- chamber (dashed line) and main-chamber (continuous line) Rate of Heat Release (RoHR) for all the measured cases. Pre-chamber RoHR is magnified by a factor of 3. Shadow for each continuous line represents plus and minus one standard deviation

Page 6 of 16 
The main-chamber heat releases rates with both combustion chamber shape reach their maximum around a similar CAD (around TDC for the reference case). Then, the RoHR decrease is different for each combustion chamber. The bowl combustion chamber presents a faster decline in the RoHR (from TDC until 5 CAD aTDC for the reference case), followed by a constant slope of RoHR decrease. Contrary to the bowl piston, the flat piston exhibits a steady decline for the final stage of the RoHR (from around 3 until 30 CAD aTDC for the reference case). The flat combustion chamber behavior resulted in a longer combustion duration than the bowl case, as presented in

Figure 12. The combustion duration in this study was defined as the difference between CA 90 and CA 10.

It is worth noting that the cumulative HR for the flat combustion chamber is always higher, and it is because of the difference in the air trapped mass of the two different compression ratios. The combustion chamber comparison was carried out with constant $\lambda_{\text {Glo }}$, PCFR, and motoring TDC pressure. With the difference in air trapped mass, the added fuel was 10\% higher for the flat piston (see Table 5). Despite this higher fueling for the flat combustion chamber, the Gross Indicated Mean Effective Pressure (IMEPg) difference between the two combustion chambers is even higher (20\%). The discrepancy could lie on the Combustion Losses Mean Effective Pressure (CLMEP), which are considerably lower for the flat combustion chamber, pointing to a more complete combustion. The definitions of the related parameters IMEPg and CLMEP are reported in the appendix A3.

Table 5 Summary of the some Mean Effective Pressure (MEP) of the tested operating modes. Piston geometry: B (Bowl), F (Flat)

\begin{tabular}{|c|c|c|c|c|c|}
\hline$\lambda_{\text {Glo }}$ & PCFR & Piston & FuelMEP & IMEPg & CLMEP \\
\hline$[-]$ & {$[\%]$} & {$[-]$} & [bar] & [bar] & [bar] \\
\hline \multirow{6}{*}{1.8} & \multirow[t]{2}{*}{6} & $\mathrm{~B}$ & 18.9 & 7.2 & 3.2 \\
\hline & & $\mathrm{F}$ & $20.8(+10 \%)$ & $8.9(+24 \%)$ & $1.8(-44 \%)$ \\
\hline & \multirow[t]{2}{*}{9} & B & 18.9 & 7.1 & 3.2 \\
\hline & & $\mathrm{F}$ & $20.8(+10 \%)$ & $8.9(+24 \%)$ & $1.8(-41 \%)$ \\
\hline & \multirow[t]{2}{*}{11} & B & 18.9 & 7.2 & 3.2 \\
\hline & & $F$ & $20.8(+10 \%)$ & $8.9(+23 \%)$ & $1.8(-44 \%)$ \\
\hline \multirow{6}{*}{2} & \multirow[t]{2}{*}{6} & $\mathrm{~B}$ & 17.4 & 6.4 & 3.5 \\
\hline & & $\mathrm{F}$ & $18.9(+10 \%)$ & $8.0(+24 \%)$ & $1.9(-44 \%)$ \\
\hline & \multirow[t]{2}{*}{9} & B & 17.3 & 6.4 & 3.5 \\
\hline & & $\mathrm{F}$ & $18.9(+10 \%)$ & $7.9(+24 \%)$ & $2.3(-41 \%)$ \\
\hline & \multirow[t]{2}{*}{11} & B & 17.3 & 6.4 & 3.5 \\
\hline & & $\mathrm{F}$ & $18.7(+10 \%)$ & $7.9(+24 \%)$ & $2.3(-45 \%)$ \\
\hline
\end{tabular}

\section{Pre-chamber Discharge process and cycles selection}

A deeper analysis of the pre-chamber discharge was performed to ensure a fair comparison between the two combustion chambers. The analysis contemplates six parameters extracted from the $\Delta P$ and its angular derivative as shown in Figure 9. Figure 13 illustrates the multiple scatter plot between four (Maximum $\triangle P$, Crank Angle of Maximum $\Delta P$, Duration of the pre-chamber discharge, and Maximum $\mathrm{d}(\Delta P) / \mathrm{d} \theta$ ) of the six parameters for the two combustion chambers. The remaining two parameters were excluded in Figure 13 for illustration purposes. Figure 13 is a symmetric matrix that the individuals scatter plots between the four variables on top of the diagonal. The histograms of each parameter are presented on the diagonal.

Page 7 of 16
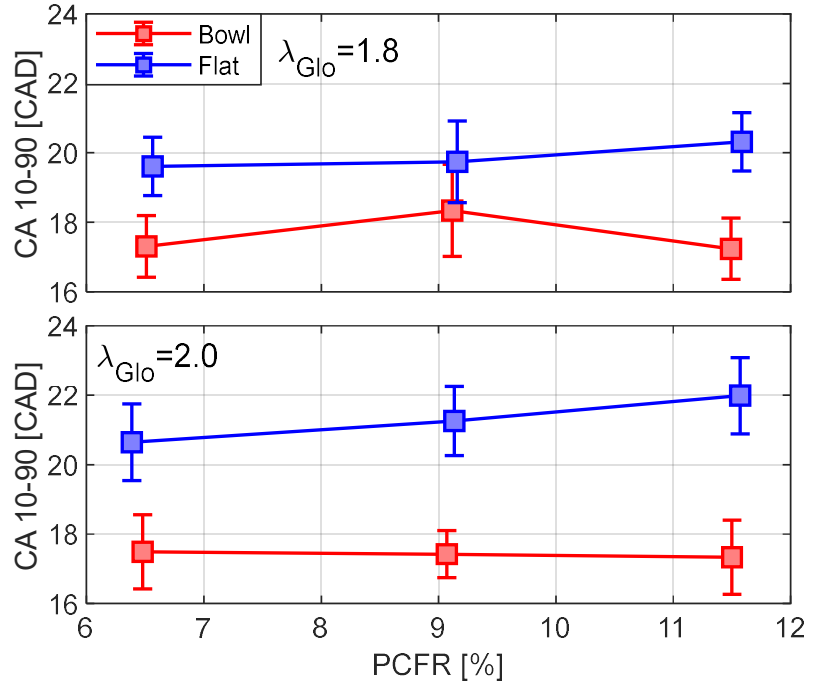

Figure 12. Combustion duration.

The scattering between all the variables is similar, the samples of the two combustion chambers occupy the same areas in all the scatter plots. Additionally, the linear correlation that presents the Maximum $\Delta P$ and the Maximum $\mathrm{d}(\Delta P) / \mathrm{d} \theta$ (top right scatter plot) for the bowl combustion chamber, is also present for the flat combustion chamber. These two statistical observations support the hypothesis of similarity of the pre-chamber discharge between the two combustion chambers.

A key parameter to have similar pre-chamber discharge is the $\lambda$ PC. The piston velocity governs the pre-chamber's filling up process during the compression stroke, which is similar for different piston geometries [26]. Then, the flow along the nozzle holes increases the fluid velocity generating a higher turbulence level. This turbulence increase is common for the two piston geometries, which indicates a similar pre-chamber filling process, which is in concordance with the evidence found by this study of similar pre-chamber discharges. Another observation from Figure 13 is the possibility to select two almost identical samples (one for each piston geometry). The selection process for the reference case ended with the cycle 49 for the Bowl piston and the cycle 24 for the Flat piston, which are considered as identical for this study (see Figure 14).

Figure 15 presents the reacting zone penetration and main-chamber RoHR for the identical cycles. The term "reacting zone" for this study is interpreted as the main-chamber reacting zone propagation, and it was determined by $\mathrm{OH}^{*}$ chemiluminescence. The reacting zone penetration and RoHR traces are parallel for the two piston geometries until the interaction in the flat combustion chamber $(-9.8$ CAD aTDC).

After this point, both reacting zone penetration and RoHR slow down for the flat piston and keep the same increase rate for the bowl piston. The jet-piston interaction for the bowl piston occurs at -8.4 CAD aTDC; after that, the reacting zone penetration stops, and the RoHR decelerates. A similar deceleration is observed for the flat piston at later $\mathrm{CAD}(-6 \mathrm{CAD}$ aTDC) when the reacting jets reach the liner. 


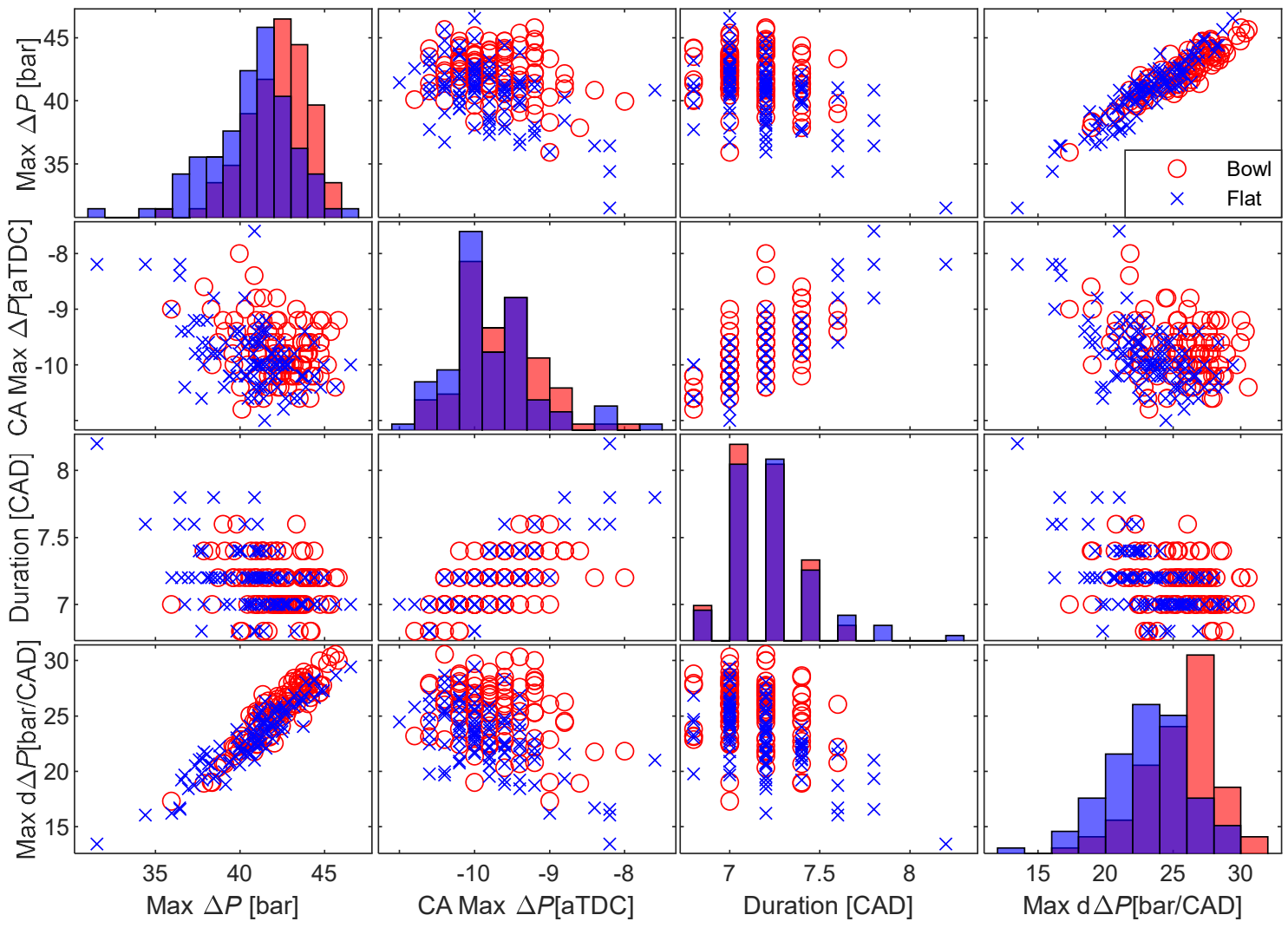

Figure 13. Plot matrix for the statistical analysis of the Pre-chamber discharge similarity for PCFR $=6 \%$ and $\lambda_{\text {Glo }}=1.8$.

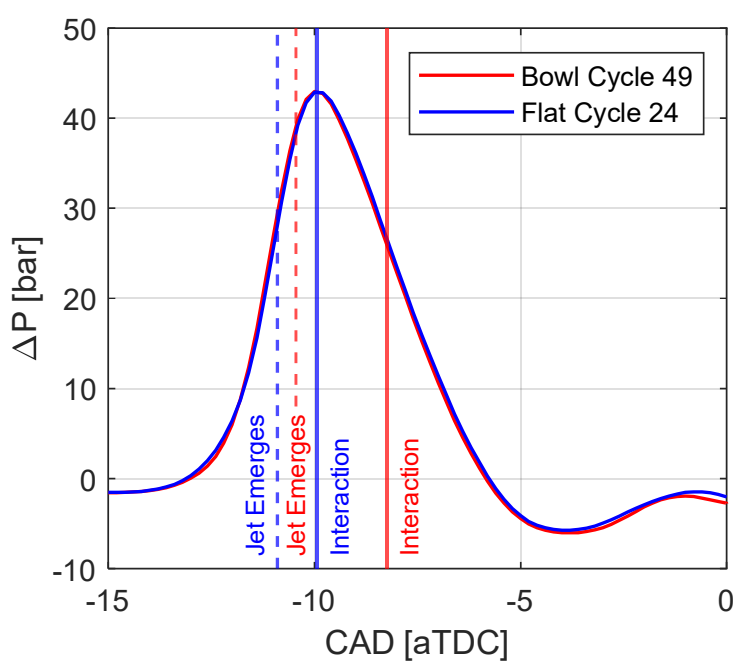

Figure 14. $\Delta P$ for the two identical cycles of the reference case

Another observation from Figure 15 is negligible the phase delay between the two penetration traces, which correspond to an identical $\Delta P$. It is expected to have a zero phase delay between the jet's profiles if there is no phase delay between the pressure profiles.

Figure 16 shows the histogram of the pressure and reacting zone penetration phase delays for the fifty pairs with the most similar cycles. The pressure phase delay is defined as the crank angle difference where the $\Delta P$ traces reach 10 bar. The reacting zone penetration phase delay is defined as the crank angle difference where the penetration traces reach $25 \mathrm{~mm}$.

Page 8 of 16
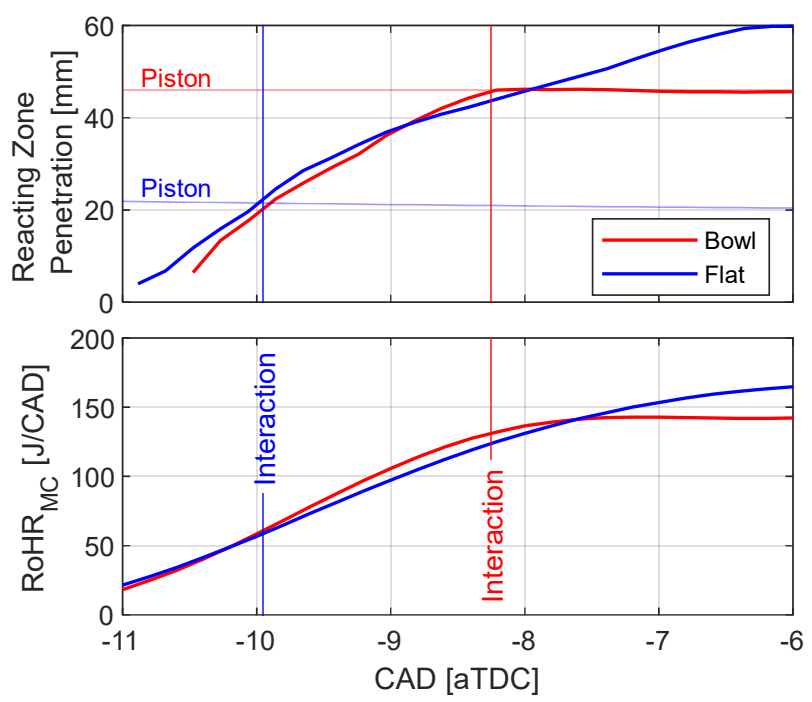

Figure 15. Reacting zone penetration and Main-Chamber RoHR for the two identical cycles $\left(\mathrm{PCFR}=6 \%\right.$ and $\left.\lambda_{\mathrm{Glo}}=1.8\right)$.

Both delays take the bowl piston event as the reference. As expected, most of the similar cycles have zero phase delay for the pressure and the reacting zone penetration profiles. The phase difference reported in Figure 15 is then considered negligible. This is likely caused by the uncertainties generated from the synchronization of the camera with the engine encoder. The camera has a time-based clock while the pressure profiles are recorded relative to CAD. 


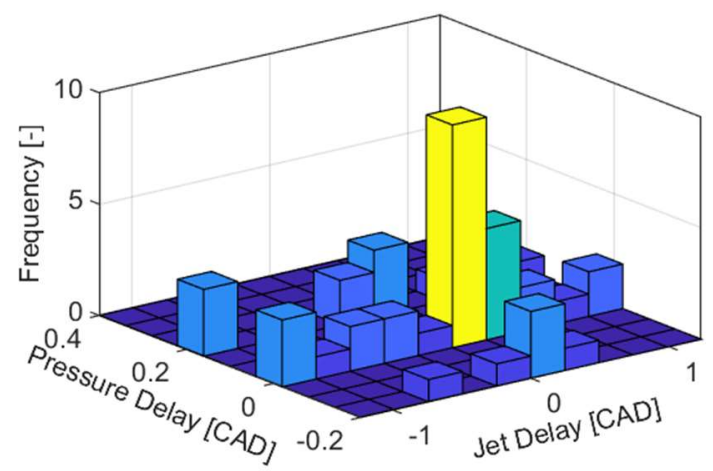

Figure 16. Histogram for the phase delay of pressure traces and phase delay of the reacting zone penetration traces. The phase delay of pressure is defined as

the difference of Crank Angle for the 10 bar and the phase delay of the
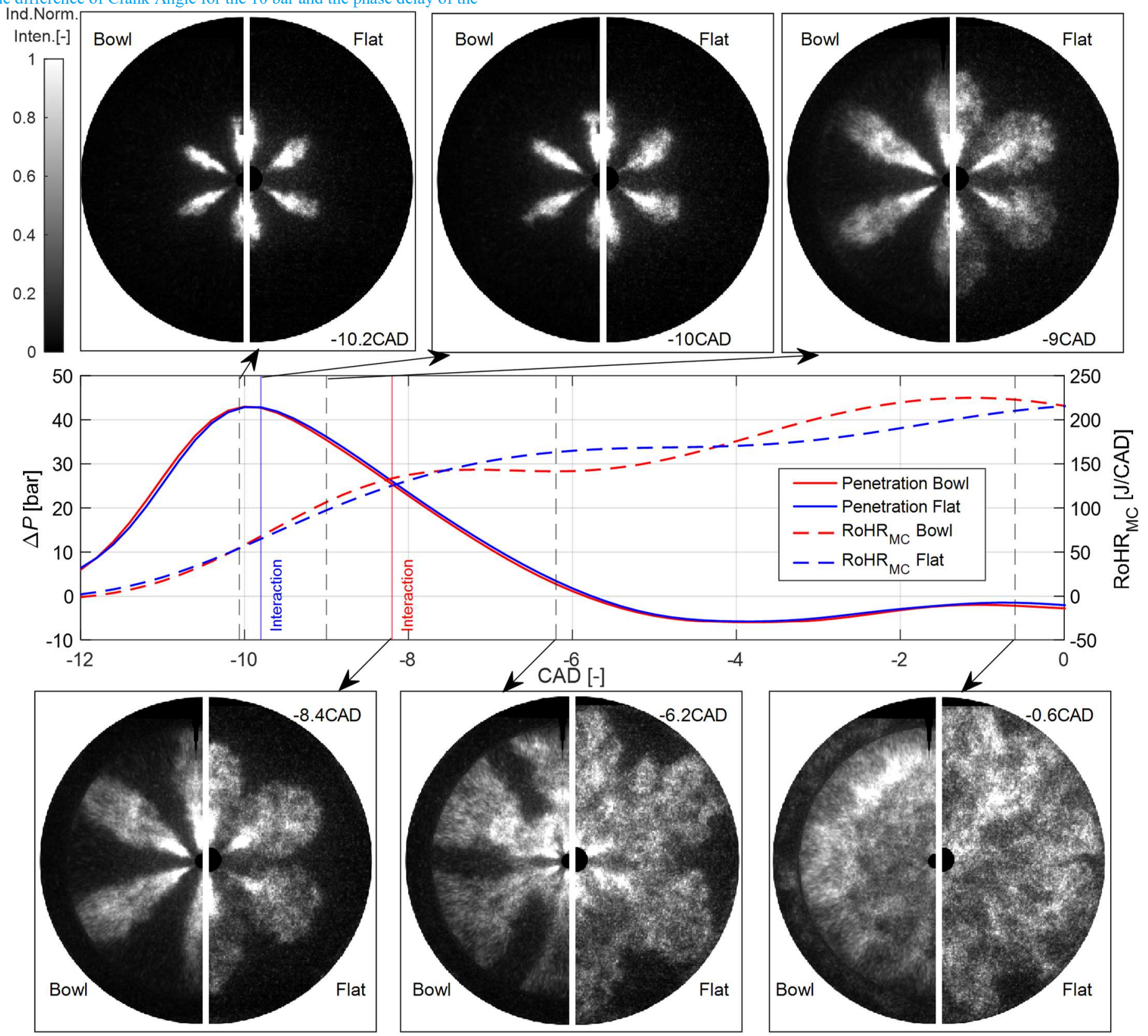

Figure 17 reports the comparison of the $\mathrm{OH}^{*}$ chemiluminescence images between the two piston at six different CAD, as well as the $\Delta P$, and the RoHR of the identical cycles. The first and second pair images show the reacting jets from both combustion chambers before interacting with the piston. The time from the reacting jet emergence until the reacting jet-piston interaction is called in this paper "Free Reacting Jet Time" (FRJT). During the FRJT, both piston images present similar jets shape. The reacting zone penetration is slightly larger for the flat combustion chamber, as it was already observed in Figure 15.

Figure 17. Graphical comparison of two the identical cycles of the reference case. Every image has been normalized by its maximum value

Page 9 of 16 
After the early interaction for the flat piston (at -9.8 CAD aTDC) the reacting jets splash out and become more disperse in that combustion chamber. The reacting jet difference after the interaction is reported in the sequence illustration of individual reacting jets shown in Figure 18. Before the interaction, the image correlation is higher than 0.6 , and after the jet-piston interaction, the correlation coefficient decreases monotonically.

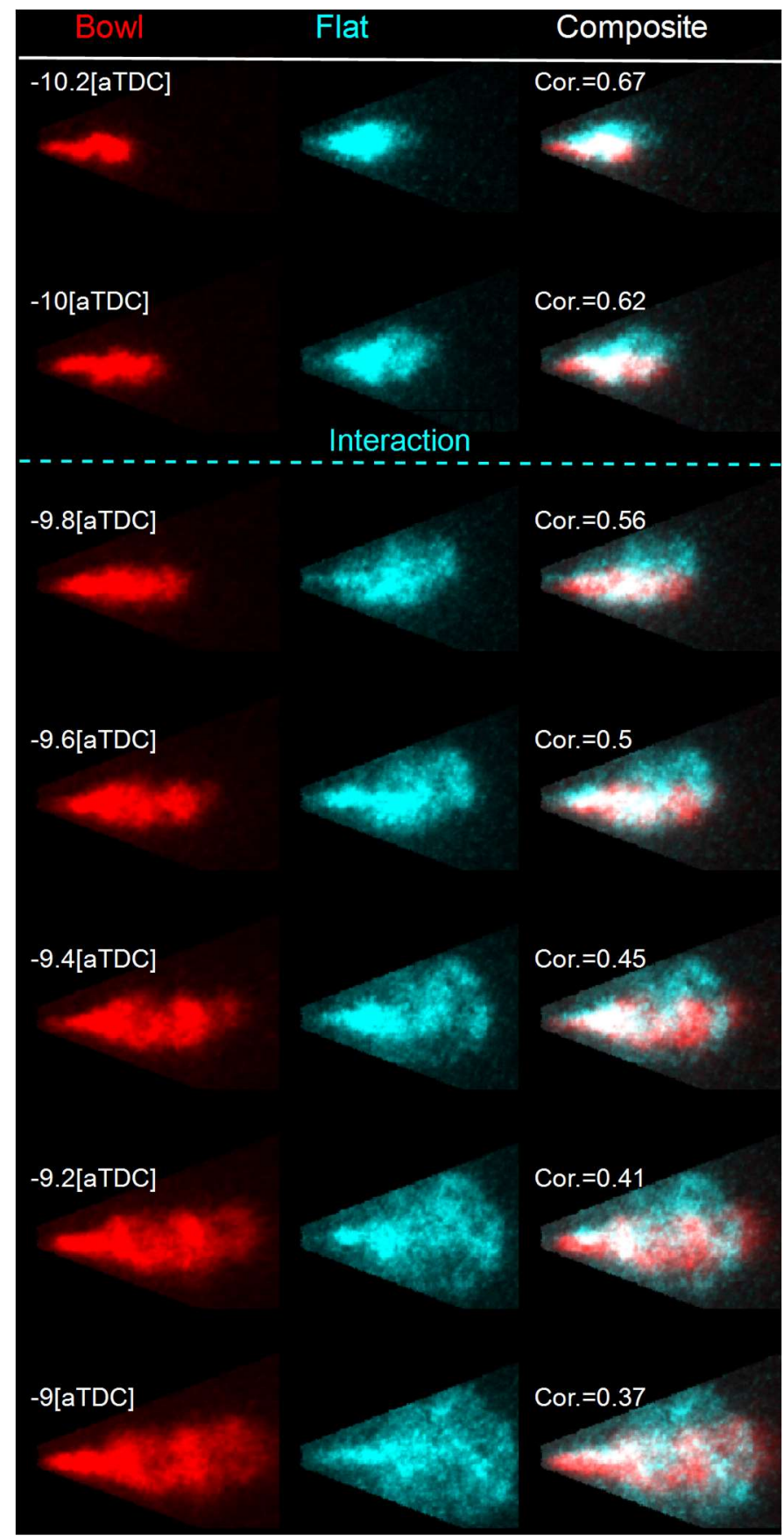

Figure 18. Reacting Jet image sequence for bowl, flat and composite Correlation is the Structural Similarity index [22].

The reacting jet impact with the piston surface also slows down the reacting zone penetration, retarding the reacting zone penetration in the flat combustion chamber. Simultaneously, the splash effect promotes the combustion of the unburned charge between the jets, as illustrated with the pair of images at -9.0 and -8.4 CAD aTDC. After the jet-piston interaction in the bowl combustion chamber, the combustion propagation decelerates because of the physical restriction of the Bowl walls. The combustion propagation from -8.4 to $-6.2 \mathrm{CAD}$ aTDC for the bowl piston is smaller than the flat piston. The bowl-in-piston image at -6.2 CAD aTDC presents luminosity only in the bowl area. Contrary, the flat piston image presents luminosity in the central part and almost reaches the liner.

The final pair of images in Figure 17 shows the combustion status close to maximum heat release. In the bowl piston case, there is very little $\mathrm{OH}$ signal in the squish zone. In contrast, in the flat combustion chamber, the combustion penetrates until the liner walls without significant intensity reduction. This result could be related to a possible incomplete combustion in the squish region of the bowl combustion chamber.

Figure 19 presents the two combustion chamber $\mathrm{HC}$ emissions results in the optical engine, and the bowl chamber tested in the homologous all-metal engine. The bowl combustion chamber presented higher specific emissions than the flat combustion chamber. Considering that the two combustion chambers have similar crevice volume (Bowl $=10.3 \mathrm{~cm}^{3}$, Flat $=9.5 \mathrm{~cm}^{3}$ ), the $\mathrm{HC}$ emissions discrepancy might come from another source. The bowl combustion chamber has a higher piston area ( $37 \%$ higher) than the flat piston, increasing the heat transfer and contributing to a possible wall quenching, especially in the squish region [31]. This possible explanation agrees with the reduction of image intensity for the bowl squish area, where the wall quenching is possibly occurring.

Regarding the optical and metal comparison, the optical engine's specific emissions are higher than the all-metal engine. This observation disagrees with the literature $[15,32,33]$, which showed lower $\mathrm{HC}$ emissions for optical engines because of the higher incylinder temperature. The cause of this disagreement is the difference of crevice and squish volumes between the tested optical and metal combustion chambers (see appendix A2). The optical configuration has more than three times the crevice volume and $40 \%$ more squish volume than the metal engine configuration. These higher volumes could be the reason for the observed trend.

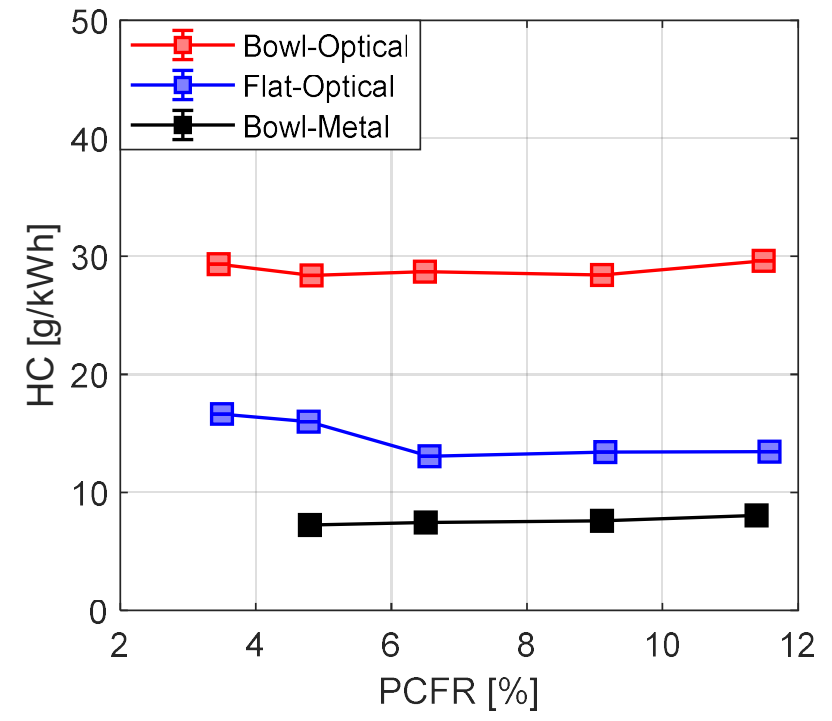

Figure 19. Specific Unburned hydrocarbon emissions,

Page 10 of 16 


\section{Free-Reacting Jet Time}

After analyzing the two combustion processes, the main conclusion is the pre-chamber discharge is the same for both pistons, which allows the use of a flat piston to study the pre-chamber jet. Nevertheless, the jet's study is comparable only when jets are free, from its emergence until the interaction with the piston surface. Figure 20 presents the scatter plot between the Crank Angle when the interaction occurs and the FRJT for all the tested cases.
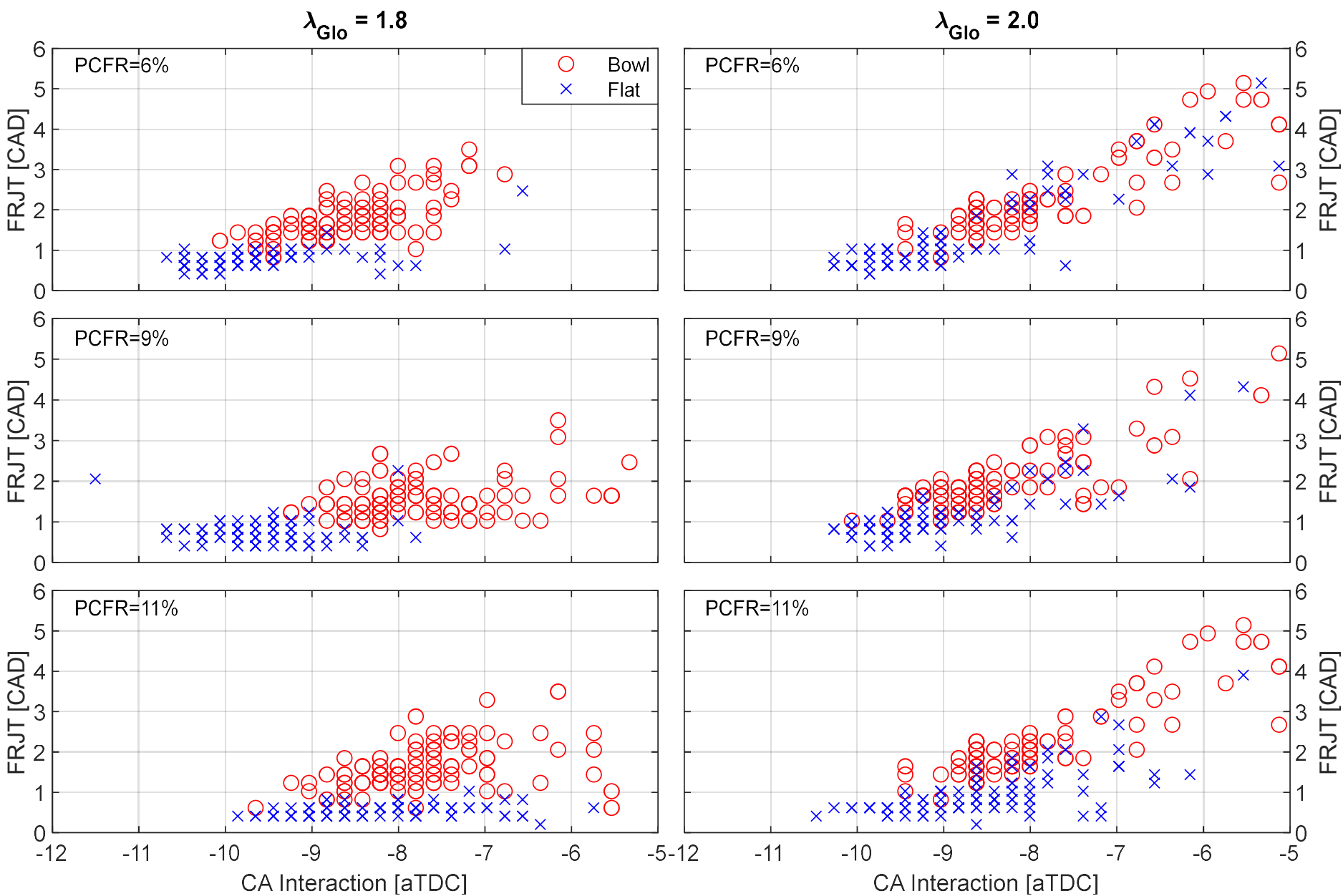

Figure 20. Scatter plots for the Free Jet Time and CA Interaction for all the six tested cases.

The flat combustion chamber always has a shorter FRJT than the bowl combustion chamber. Even, for richer cases, $\mathrm{PCFR}=11 \%$ and $\lambda_{\mathrm{Glo}}=1.8$, the FRJT presents small values. Lean cases exhibited relatively longer FRJT, and they should be selected to study the prechamber jets using a flat piston.

Finally, Figure 21 shows the average of the FRJT for all the tested cases. In general, the flat combustion chamber's FRJT is between 30$50 \%$ of the total FRJT of the reference bowl combustion chamber. The obtained results suggest testing leaner cases when a flat is used.

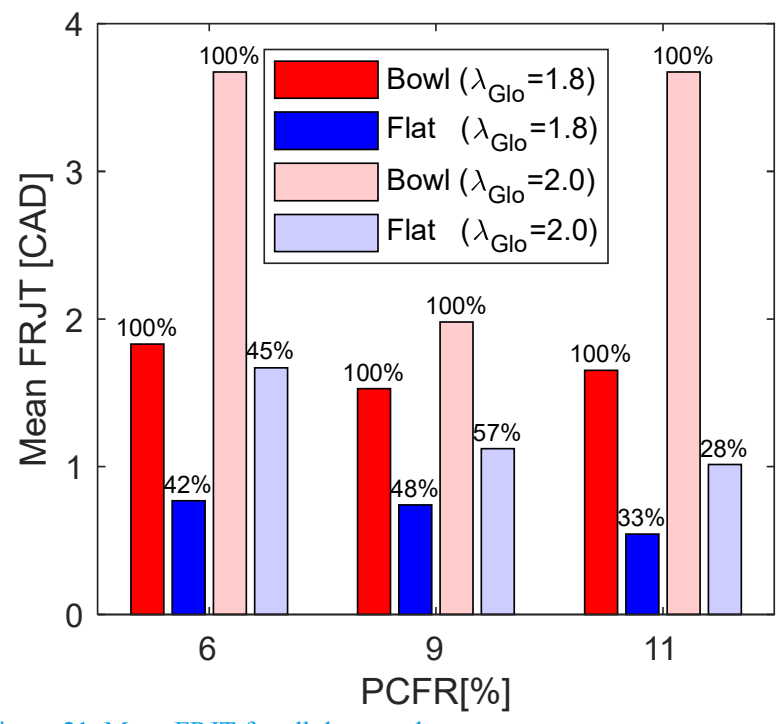

Figure 21. Mean FRJT for all the tested cases

Page 11 of 16 


\section{Conclusions}

The present study addressed the differences between a bowl and flat combustion chambers for pre-chamber reacting jet analysis. The main conclusions of the study are:

1. For the pre-chamber discharge process, there is no significant difference between the two combustion chambers. The flat piston does not modify the pre-chamber pressure increase due to the combustion, ending in similar $\Delta P$.

2. The Free Reacting Jet Time (FRJT) for the flat combustion chamber is around $30-50 \%$ of the bowl combustion chamber's free reacting jet time. The reduction is caused by the early jet-piston interaction due to the shorter jet path in the flat piston geometry.

3. Regarding the flat piston, leaner cases have longer free reacting jet time, and they should be selected to study the pre-chamber jets when a flat piston is used.

4. The initial deceleration points observed in the rate of heat release are related to the deceleration of the reacting jet. The flat combustion chamber exhibited two deceleration points, one for the early jet-piston interaction and a second one for the liner interaction. The bowl piston exhibited one for the reacting jet interaction with the bowl rim.

5. The bowl combustion chamber has a lower luminosity in the squish area and shows higher $\mathrm{HC}$ emissions than the flat piston. A possible incomplete combustion in the squish volume appears to the culprit of high $\mathrm{HC}$ emissions in the bowl piston geometry.

6. Optical bowl piston also presented higher $\mathrm{HC}$ emissions to its homologous metal engine configuration. The difference could lie in having larger crevices and squish volume.

7. The combustion duration of the flat piston was longer to bowl piston. The squish area in the bowl combustion chamber exhibited less combustion chemiluminescence, which ended in an incomplete combustion, which has shorter duration related to the flat piston combustion chamber.

\section{References}

1. Parliament ,E. "DIRECTIVE (EU) 2019/1161 OF THE EUROPEAN PARLIAMENT AND OF THE COUNCIL of 20 June 2019 amending Directive 2009/33/EC on the promotion of clean and energy-efficient road transport vehicles". 2019:15.

2. Bunce ,M., Blaxill ,H., Kulatilaka ,W., Jiang, N. "The effects of turbulent jet characteristics on engine performance using a pre-chamber combustor". SAE Technical Paper 2014-01-1195, 2014, doi:10.4271/2014-01-1195

3. Correale ,G., Rakitin ,A., Nikipelov ,A., et al. "Nonequilibrium plasma ignition for internal combustion engines". SAE Technical Papers 2011-24-0090, 2011,
4. Dale ,J.D., Smy ,P.R., Clements ,R.M. "Laser ignited internal combustion engine - An experimental study". SAE Technical Paper 780329, 1978, doi:10.4271/780329

5. Sher ,E., Ben-Ya'Ish ,J., Pokryvailo ,A., Spector, Y. "A corona spark plug system for spark-ignition engines". SAE Technical Paper 920810,1992, doi:10.4271/920810

6. Attard ,W., Blaxill ,H. "A Single Fuel Pre-Chamber Jet Ignition Powertrain Achieving High Load, High Efficiency and Near Zero NOx Emissions". SAE Technical Paper 201101-2023, 2011, doi:10.4271/2011-01-2023

7. Biswas ,S., Tanvir ,S., Wang ,H., Qiao ,L. "On ignition mechanisms of premixed CH4/air and H2/air using a hot turbulent jet generated by pre-chamber combustion". Appl Therm Eng. 2016;106:925-937. doi:10.1016/j.applthermaleng.2016.06.070

Gentz ,G.R., Gholamisheeri ,M., Toulson ,E. "A study of a turbulent jet ignition system fueled with iso-octane: Pressure trace analysis and combustion visualization". Appl Energy. 2017;189:385-394. doi:10.1016/j.apenergy.2016.12.055

9. Shah ,A., Tunestal ,P., Johansson ,B. "Effect of PreChamber Volume and Nozzle Diameter on Pre-Chamber Ignition in Heavy Duty Natural Gas Engines". SAE Technical Paper 2015-01-0867, 2015, doi:10.4271/2015-010867

10. Gholamisheeri ,M., Thelen ,B.C., Gentz ,G.R., Wichman ,I.S., Toulson ,E. "Rapid compression machine study of a premixed, variable inlet density and flow rate, confined turbulent jet". Combust Flame. 2016;169:321-332. doi:10.1016/j.combustflame.2016.05.001

11. Gholamisheeri ,M., Wichman ,I.S., Toulson ,E. "A study of the turbulent jet flow field in a methane fueled turbulent jet ignition (TJI) system". Combust Flame. 2017;183:194-206. doi:10.1016/j.combustflame.2017.05.008

12. Vedula ,R.T., Gentz ,G., Stuecken ,T., Toulson ,E., Schock „H. "Lean Burn Combustion of Iso-Octane in a Rapid Compression Machine Using Dual Mode Turbulent Jet Ignition System". SAE Int J Engines. 2018;11(1):03-11-010007. doi:10.4271/03-11-01-0007

13. Aronsson ,U., Chartier ,C., Horn ,U., Andersson ,Ö., Johansson ,B., Egnell ,R. "Heat release comparison between optical and all-metal HSDI diesel engines". SAE Technical Paper 2008-01-1062, 2008. doi:10.4271/2008-01-1062

14. Colban ,W.F., Kim ,D., Miles ,P.C., et al. "A detailed comparison of emissions and combustion performance between optical and metal single-cylinder diesel engines at low temperature combustion conditions". SAE Int J Fuels Lubr. 2009;1(1):505-519. doi:10.4271/2008-01-1066

15. Kashdan ,J.T., Thirouard ,B. "A comparison of combustion and emissions behaviour in optical and metal single-cylinder diesel engines". SAE Technical Paper 2009-01-1963, 2009,

Page 12 of 16 
doi:10.4271/2009-01-1963.

16. Kashdan ,J., Thirouard ,B. "Optical Engines as Representative Tools in the Development of New Combustion Engine Concepts". Oil Gas Sci Technol. 2011;66(5):759-777. doi:10.2516/ogst/2011134

17. Bowditch,F.W. "A new tool for combustion research a quartz piston engine". SAE Technical Paper 610002, 1961, doi: $10.4271 / 610002$

18. Gehmlich ,R.K., Dumitrescu ,C.E., Wang ,Y., Mueller ,C.J. "Leaner Lifted-Flame Combustion Enabled by the Use of an Oxygenated Fuel in an Optical CI Engine". SAE Int J Engines. 2016;9(3). doi:10.4271/2016-01-0730

19. Liu ,J., Dumitrescu ,C.E. "Flame development analysis in a diesel optical engine converted to spark ignition natural gas operation". Appl Energy. 2018;230:1205-1217. doi:10.1016/j.apenergy.2018.09.059

20. Echeverri Marquez ,M., Hlaing ,P., Tang, Q., et al. "HighSpeed Imaging of Main-Chamber Combustion of a Narrow Throat Pre-Chamber under Lean Conditions". SAE Technical Paper 2020-01-2081, 2020, doi:10.4271/2020-012081.

21. Tang,Q., An ,Y., Raman ,V., et al. "Experimental study on the effects of spray-wall interaction on partially premixed combustion and engine emissions". Energy and Fuels. 2019;33(6):5673-5681.

doi:10.1021/acs.energyfuels.9b00602

22. Wang ,Z., Bovik ,A.C., Sheikh ,H.R., Simoncelli ,E.P. "Image quality assessment: From error visibility to structural similarity". IEEE Trans Image Process. 2004;13(4):600612. doi:10.1109/TIP.2003.819861

23. Hlaing ,P., Echeverri Marquez ,M., Bhavani Shankar ,V.S., Cenker ,E., Ben Houidi ,M., Johansson ,B. "A Study of Lean Burn Pre-Chamber Concept in a Heavy Duty Engine". SAE Technical Paper 2019-24-0107, 2019, doi:10.4271/2019-240107

24. Hlaing ,P., Echeverri Marquez ,M., Singh ,E., Cenker ,E., Ben Houidi ,M., Johansson ,B. "Effects of Pre-chamber Enrichment on Lean Burn Pre-chamber Spark Ignition Combustion with a Narrow-throat Geometry". SAE Technical Paper 2020-01-0825, 2020, doi:10.4271/2020-010825

25. Almatrafi ,F., Hlaing ,P., Echeverri Marquez ,M., Ben Houidi ,M., Johansson ,B. "Narrow-Throat Pre-Chamber Combustion with Ethanol, a Comparison with Methane". SAE Technical Papers 2020-01-2041, 2020, doi:10.4271/2020-01-2041

26. Johansson ,B., Olsson ,K. "Combustion chambers for natural gas Si engines part I: Fluid flow and combustion". SAE Technical Paper 950469, 1995, doi:10.4271/950469

27. Hlaing ,P., Echeverri Marquez ,M., Cenker ,E., Houidi ,M. Ben, Johansson ,B. "Analysis of Fuel Properties on Main

Page 13 of 16
Chamber Combustion Characteristics in a Narrow-throat Pre-chamber Engine". SAE Technical Paper 2019-01-0474, 2021, doi:10.4271/2019-24-0107

28. Duong ,J., Wellander ,R., Hyvönen ,J., et al. "High Speed Combustion Imaging in a Large Bore Gas Engine: The Relationship Between Pre- and Main Chamber Heat Release". Volume 8A: Heat Transfer and Thermal Engineering. ASME; 2014:V08AT09A022. doi:10.1115/imece2013-64286

29. Tang, Q., Sampath ,R., Echeverri Marquez ,M., et al. "Simultaneous Negative PLIF and $\mathrm{OH}^{*}$ Chemiluminescence Imaging of the Gas Exchange and Flame Jet from a Narrow Throat Pre-Chamber". SAE Technical Papers 2020-012080, 2020, doi:10.4271/2020-01-2080

30. Gussak ,L.A., Karpov ,V.P., Tikhonov ,Y. V. "The Application of Lag-Process in Prechamber Engines". SAE Technical Paper 790692, 1979, doi:10.4271/790692

31. Olsson ,K., Johansson ,B. "Combustion chambers for natural gas Si engines part 2: Combustion and emissions". SAE Technical Paper 950517, 1995, doi:10.4271/950517

32. Liu ,J., Dumitrescu,C. "CFD Simulation of Metal and Optical Configuration of a Heavy-Duty CI Engine Converted to SI Natural Gas. Part 1: Combustion Behavior". SAE Technical Paper 2019-01-0002, 2019, doi:10.4271/2019-01-0002

33. Liu ,J., Dumitrescu,C. "CFD Simulation of Metal and Optical Configuration of a Heavy-Duty CI Engine Converted to SI Natural Gas. Part 2: In-Cylinder Flow and Emissions". SAE Technical Paper 2019-01-0003, 2019, doi:10.4271/2019-01-0003

34. Johansson ,B. Combustion Engines, Volume 1. Lund University; 2014.

\section{Contact Information}

\author{
Manuel Alejandro Echeverri Marquez \\ Ph.D. Candidate \\ Clean Combustion Research Center (CCRC) \\ Internal Combustion Engine Lab \\ King Abdullah University of Science and Technology (KAUST) \\ Thuwal, Saudi Arabia \\ manuel.echeverrimarquez@,kaust.edu.sa \\ Phone no: +966 568320831

\section{Acknowledgments}

The paper is based upon work supported by Saudi Aramco Research and Development Center FUELCOM3 program under Master Research Agreement Number 6600024505/01. FUELCOM (Fuel Combustion for Advanced Engines) is a collaborative research undertaking between Saudi Aramco and KAUST intended to address the fundamental aspects of hydrocarbon fuel combustion in engines and develop fuel/engine design tools suitable for advanced combustion modes. 
Definitions/Abbreviations

PCC

SI

PCFR

$\lambda$

CAD

RPM

$\Delta P$

ICE

TDC

MC

PC

SOI

BDC

TDC
Pre-chamber Combustion

Spark Ignition

Pre-chamber Fuel Ratio

Air-fuel ratio / (Air-fuel

Ratio) $)_{\text {stoichiometric }}$

Crank Angle Degree

Revolutions per minute

Pre- and main-chamber pressure difference

Internal Combustion Engines

Top Dead Center

Main-Chamber

Pre-chamber

Start of Injection

Bottom Dead Center

Top Dead Center
aTDC

$\boldsymbol{\theta}$

HR

RoHR

FuelMEP

QMEP

IMEPg

CLMEP

FRJT

CA10

CA90

HC
After Top Dead Center

Crank Angle

Heat Release

Rate of Heat Release

Fuel Mean Effective

Pressure

Heat Mean Effective Pressure

Gross Indicated Mean Effective Pressure

Combustion Losses Mean Effective Pressure

Free Reacting Jet Time

Crank Angle of $10 \%$ of heat release

Crank Angle of $90 \%$ of heat release

Hydrocarbon 


\section{Appendix}

\section{A1. Bowl Piston geometry comparison: Optical and Metal}

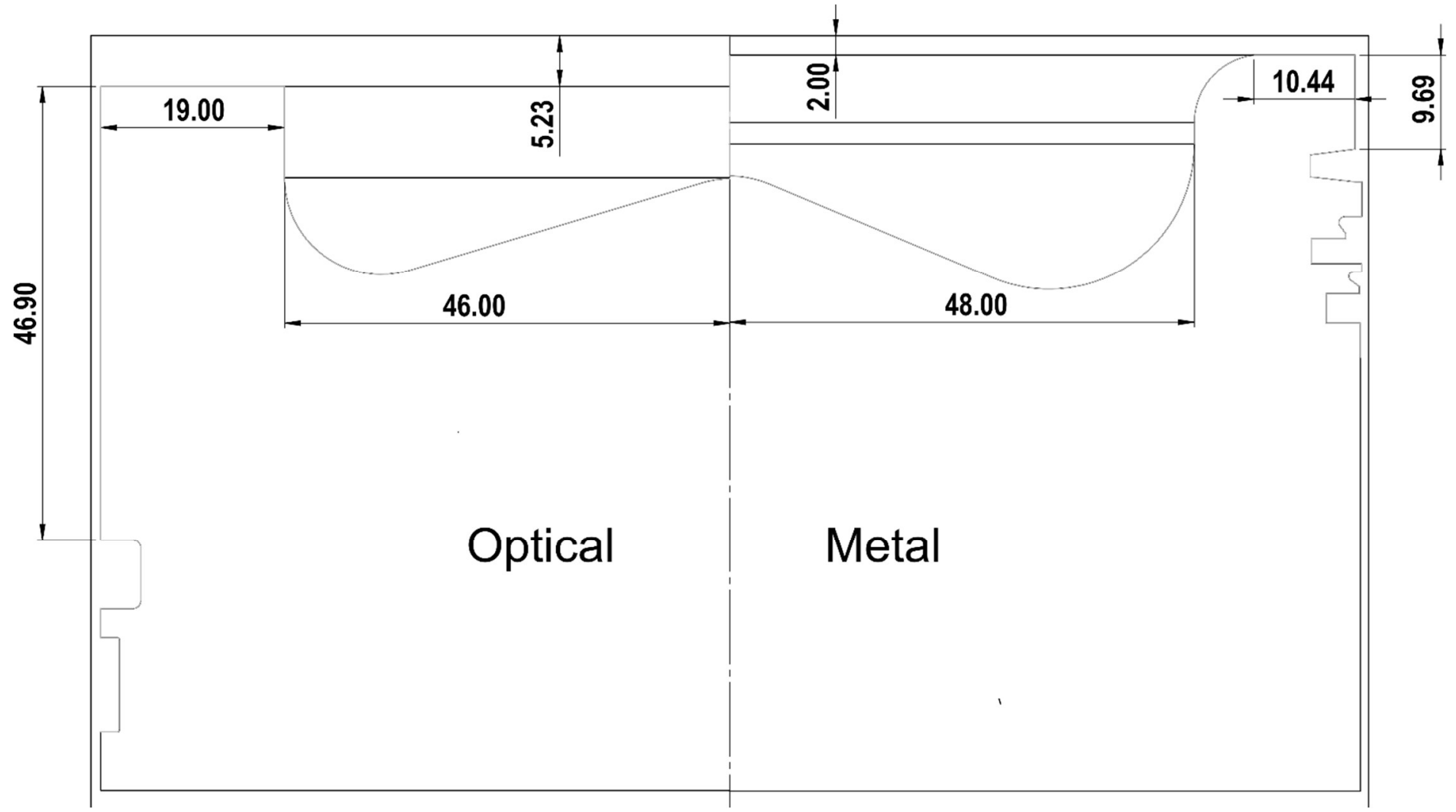

\section{A2. GT-Power Model}

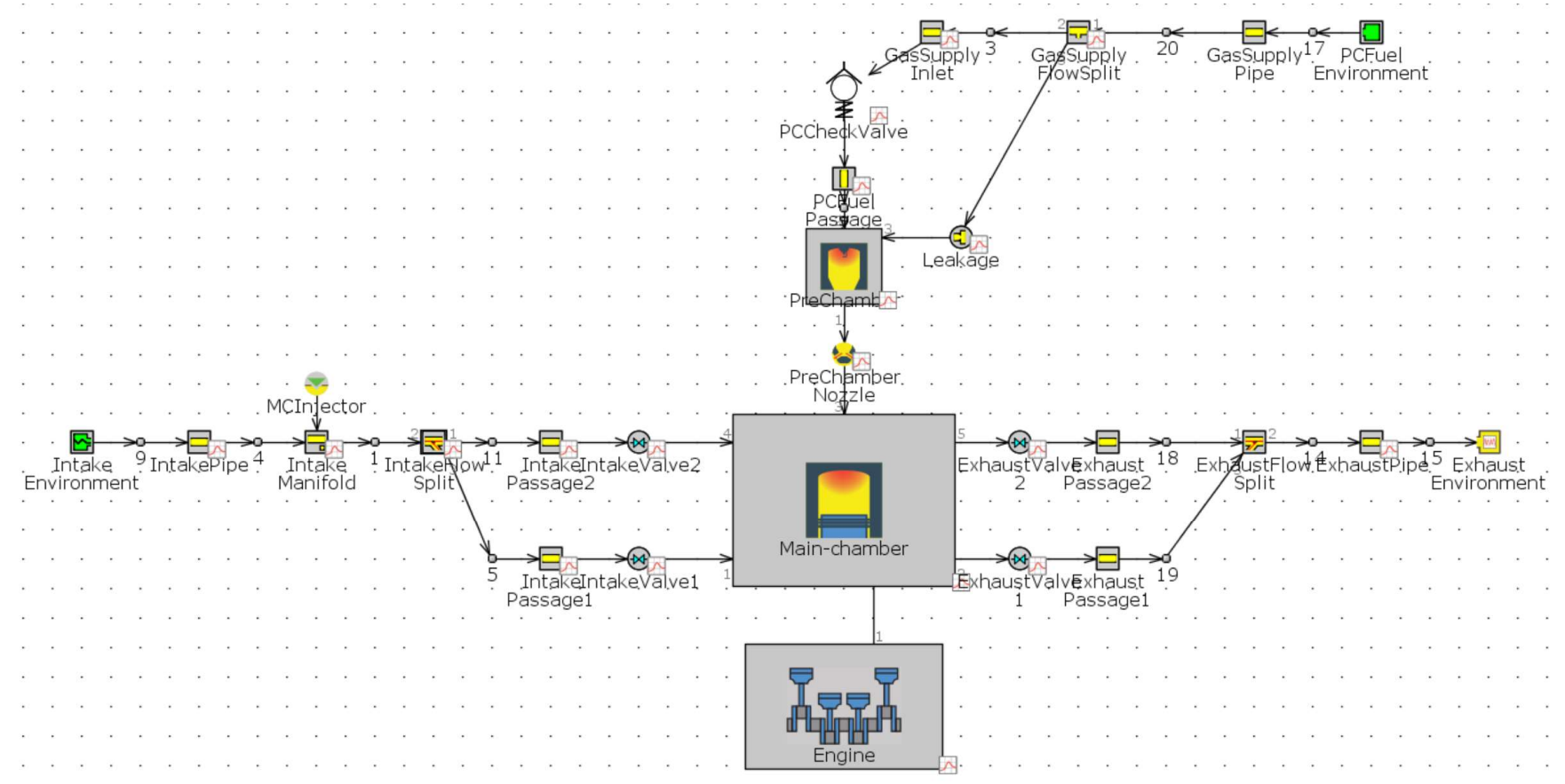

Page 15 of 16 


\section{A3. Mean Effective Pressure Definitions}

The Mean Effective Pressures that were used in this manuscript are based on the definitions proposed by Johansson et al. [34]. The principle takes references on the Sankey diagram of the conversion of the fuel energy to brake energy that occurs in an engine.

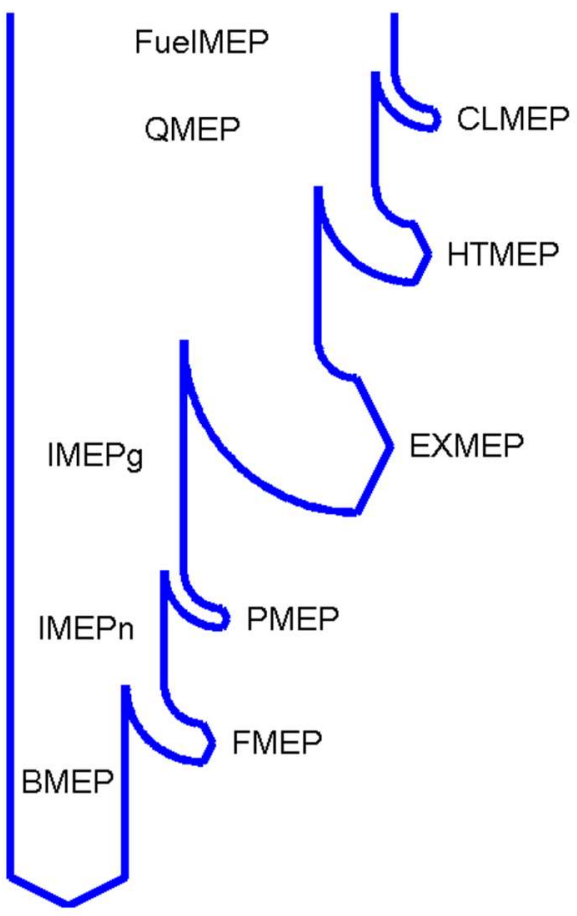

\section{Fuel Mean Effective Pressure (FuelMEP)}

The FuelMEP is defined as the energy content on the fuel, divided by the engine displacement (V). In this case the fuel energy is the mass of fuel multiplied by the Low Heating Value (LHV).

$$
\text { FuelMEP }=\frac{\text { mass of fuel } \times L H V}{V}
$$

\section{Heat Mean Effective Pressure (QMEP)}

The heat mean effective pressure is defined as the heat (Q) that is released by the fuel in the cylinder, divided by the engine displacement (V).

$$
Q M E P=\frac{Q}{V}
$$

\section{Combustion Losses Mean Effective Pressure (CLMEP)}

The CLMEP is defined as the difference between the FuelMEP and the QMEP.

$$
C L M E P=\text { FuelMEP }- \text { QMEP }
$$

\section{Gross Indicated Mean Effective Pressure (IMEPg)}

The definition of the IMEPg is the work of the compression (Wc) and expansion (We) strokes, divided by the engine displacement (V).

$$
I M E P g=\frac{W c+W e}{V} \quad W c=\int_{B D C}^{T D C} p d V \quad W e=\int_{T D C}^{B D C} p d V
$$

Page 16 of 16 